\title{
Application of Predictive Control Strategies to the Management of Complex Networks in the Urban Water Cycle
}

\author{
Carlos Ocampo-Martinez*, Vicenç Puig, Gabriela Cembrano, and Joseba Quevedo
}

The management of the urban water cycle (UWC) is a subject of increasing interest because of its social, economic and environmental impact. The most important issues include the sustainable use of limited resources and the reliability of service to consumers with adequate quality and pressure levels, as well as the urban drainage management to prevent flooding and polluting discharges to the environment.

Climate change is expected to produce regional changes in water availability in the 21 st century. For example, Northern and Southern Europe are expected to experience, respectively, an increase and a decrease in mean precipitation, as well as an increase in the magnitude and frequency of extreme events [1]. These changes will have direct consequences through impacts on the availability and quality of water in the water cycle. Optimal management strategies for the systems in the water cycle can contribute to reduce the vulnerability of urban water systems (UWS) to climatic variability and change.

An UWC is mainly comprised of the following systems:

(i) Supply/production: water supply from superficial or underground sources and treatment to achieve necessary quality levels,

(ii) transport networks, which use natural or artificial open-flow channels and/or pressurized conduits to deliver water from the treatment plants to the consumer areas,

(iii) water distribution to consumers, involving pressurized pipeline networks, storage tanks, booster pumps and pressure/flow control valves,

(iv) urban drainage and sewer systems carrying waste- and rain water together to wastewater treatment plants (WWTP), before returning it to the receiving environment.

In urban environments, drinking water is provided by means of a drinking water network (DWN) to consumers and industry, and sanitation/urban drainage is achieved through a sewer network (SN). In a large number of cities, DWNs are managed using telemetry and telecontrol systems which provide, in real time, pressure, flow, quality and other measurements at several key locations within the network. Flow, pressure and storage control elements are operated from a central dispatch in a centralized or decentralized scheme.

In some cases, advanced urban drainage systems also include sewage control infrastructure, such as detention tanks, pumps, gates and weirs. All these elements are monitored and controlled by using telemetry/telecontrol systems, which involve rain-gauge networks, wastewater level and/or flow meters in the sewers and actuators at the valves, pumps and weirs, a communication network, and monitory and control software. The control system manages the flows and the storage in the network in order to minimize the risk of untreated water overflows to the streets or to the receiving environment.

The use of optimal control for managing water systems to achieve energy efficiency, cost minimization and environmental protection is summarized in this article. Applying optimal control concepts to water systems requires the development of control-oriented dynamic models to represent open-channel systems (such as rivers, canals, aqueducts or SNs), pressurized pipes or combinations of both, which have nonlinear responses to control actions, such as changing modes at different operating points. Those systems also contain storage and control elements, such as tanks and valves, with a pre-determined operational range,

${ }^{*}$ Corresponding Author: Technical University of Catalonia (UPC), Institut de Robòtica i Informàtica Industrial (CSIC-UPC), Llorens i Artigas, 4-6, 08028 Barcelona (Spain), cocampo@iri.upc.edu 
which leads to the inclusion of physical constraints in the model. Additionally, some on-off elements such as pumps or valves may exist.

The management of UWS must be carried out predictively. Control actions must be computed ahead in time, with an appropriate time horizon, based on real measurements and on state estimation, as well as predictions of the stochastic variables involved in the models such as consumer demands in drinking water systems or rain intensities in urban drainage systems. For water distribution networks, the prediction horizon is usually of 24 hours. Longer horizons are chosen for water supply and treatment management. For real-time control of urban drainage systems, the horizons depend on the average sewage transport time between the discharge points and the final collection/treatment/discharge points. Thus, the length of those horizons results to be particular for each case-study application, mainly depending on topographic and physical characteristics of the terrain and the sewers. Predictive and optimal control techniques are a smart option to compute control strategies for these complex dynamic systems. In order to achieve certain control goals, one or more optimization problems are posed using a cost function to represent control goals and a set of constraints to take into account the system dynamics and physical and operating limits. Predictive and optimal control techniques also allow the user to establish priorities among the different control objectives, whenever these cannot be achieved simultaneously [2].

Over the past few years, Model Predictive Control (MPC) has proven to be one of the most effective and accepted control strategies for large-scale complex systems [3], [4]. The objective of using this technique for controlling UWS is to compute, in a predictive way, the manipulated inputs in order to achieve the optimal performance of the network according to a given set of control objectives and predefined performance indices. As shown in [5], [6], [7], [8], such controllers are suitable to be used in the global/supervisory control of networks related to the urban water cycle. Figure 1 shows a conceptual scheme for a hierarchical structure considered on the control of networks related to the UWC.

This article summarizes the real-time global optimal management of two systems of the UWC, both of them located in Barcelona, Spain: its DWN - specifically the transport network - and a representative portion of its SN. Real-time control (RTC) of both types of UWC systems has received special attention during the last few years, due to the increasing demand for improved system performance to meet consumer and regulatory needs, often at reduced cost [5], [11]. The main goal to be achieved in DWNs is to reduce pumping costs - for instance, by filling tanks in low tariff periods - while maintaining adequate system pressure to meet fluctuating consumer demands [12]. Similarly, in urban drainage management, the goals are to minimize flooding and combined sewer overflow to the receiving environment (CSO) by controlling flow within the wastewater system, through for example, inline storage [13] or using underground detention tanks, gates and pumps [6], [14].

\section{Control-Oriented Modeling Principles}

Complex nonlinear models are very useful for off-line operations (for instance, calibration and simulation). Detailed mathematical representations such as the Saint-Venant equations for describing the openflow behavior in SNs [15] or pressure-flow models for DWNs allow the simulation of those systems with enough accuracy to observe specific phenomena, useful for design and investment planning. However, for on-line computation purposes such as those related to global management, a simpler and control-oriented model structure must be conveniently selected. This simplified model includes the following features:

(i) Representativeness of the main network dynamics: It must provide an evaluation of the main representative hydrological/hydraulic variables of the network and their response to control actions at the actuators.

(ii) Simplicity, expandability, flexibility and speed: It must use the simplest approach capable of achieving the given purposes, allowing very easily to expand and/or modify the modeled portion of the network.

(iii) Amenability to on-line calibration and optimization: this modeling approach must be easily calibrated on-line using data from the telemetry system and embedded in an optimization problem to achieve the network management objectives. 


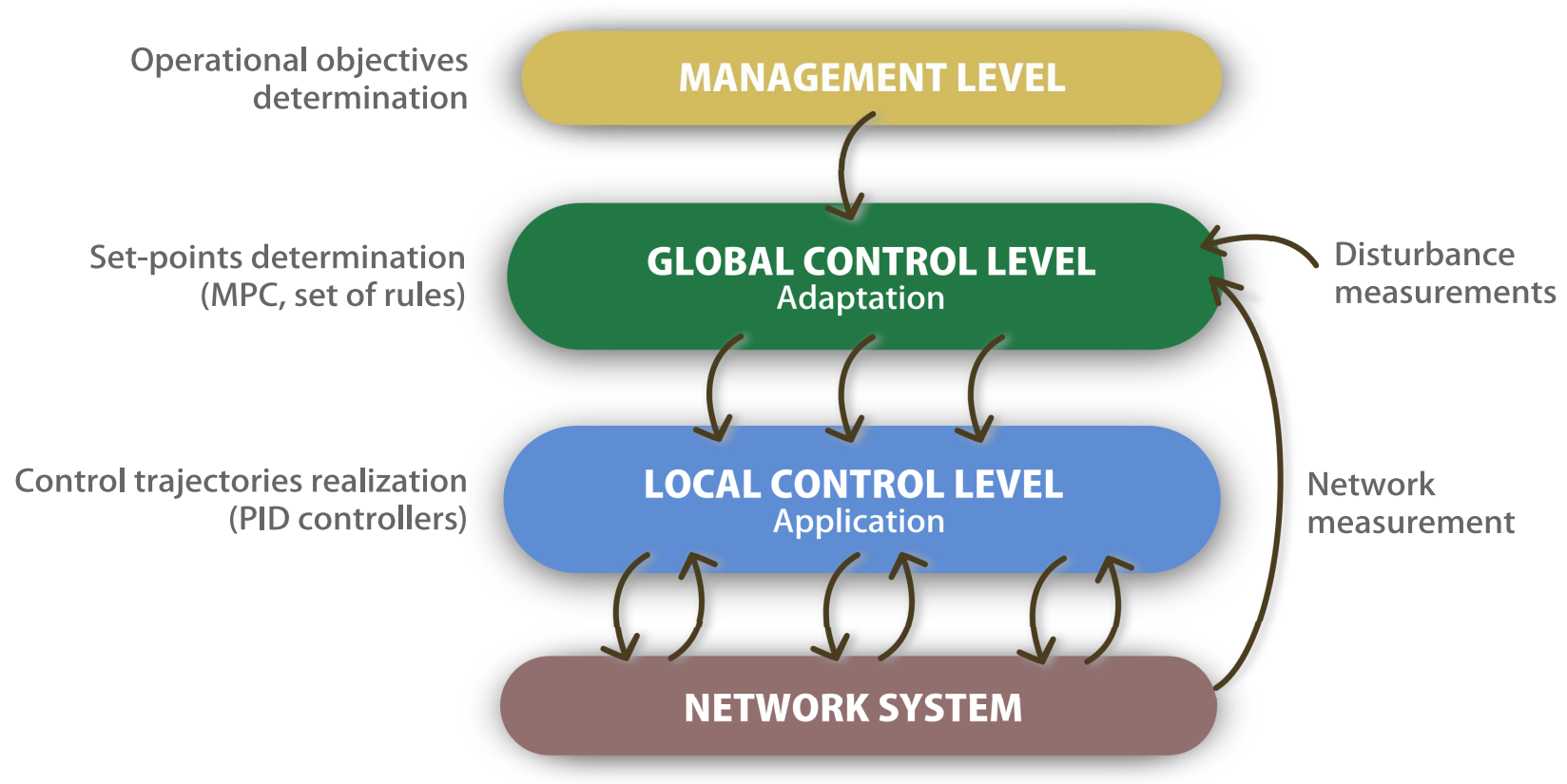

Fig. 1. Hierarchical structure for RTC system. Adapted from [9] and [7]. Here, the MPC, as the global control law, determines the references (set points) for the local controllers placed at different elements of the networked system. These references are computed according to measurements taken from sensors distributed around the network. The management level provides the MPC with its operational objectives, which are reflected in the controller design as the performance indices to be enhanced, which can be either minimized or maximized, depending on the case. Finally, water systems control requires the use of a supervisory system to monitor the performance of the different control elements in the networks (sensors and actuators) and to take appropriate correcting actions in the case where a malfunction is detected, to achieve a proper fault-tolerant control [10].

This section deals with the control-oriented model principles for the DWN and SN systems described in this article. The distinction is done at the stage of component description while the structure of the model from the merging of elements is described and discussed in a unified way for both systems, determining then the correspondence of their variables with the common variables established in the control theory.

\section{A. Drinking Water Networks (DWN)}

Several modeling techniques dealing with DWNs have been presented in the literature; see, e.g., [16], [15]. Here, a control-oriented modeling approach that considers a flow-model is outlined, which follows the principles presented by the authors in [5], [6] and [17]. The extension to include the pressure-model can be found in [16], [15], [18]. A DWN generally contains a set of pressurized pipes, water tanks at different elevation, and a number of pumping stations and valves to manage water flows, pressure and elevation in order to supply water to consumers.

The DWN model can be considered as composed of a set of constitutive elements, which are presented and discussed below. Figure 2 shows, in a small example, the interconnection of typical constitutive elements.

1) Tanks: Water tanks provide the entire DWN with the storage capacity of drinking water at appropriate elevation levels to ensure adequate water pressure service to consumers. The mass balance expression relating the stored volume $v$ in the $n$-th tank can be written as the discrete-time difference equation

$$
v_{n}(k+1)=v_{n}(k)+\Delta t\left(\sum_{j} q_{\text {in }}^{j n}(k)-\sum_{h} q_{\text {out }}^{n h}(k)\right),
$$




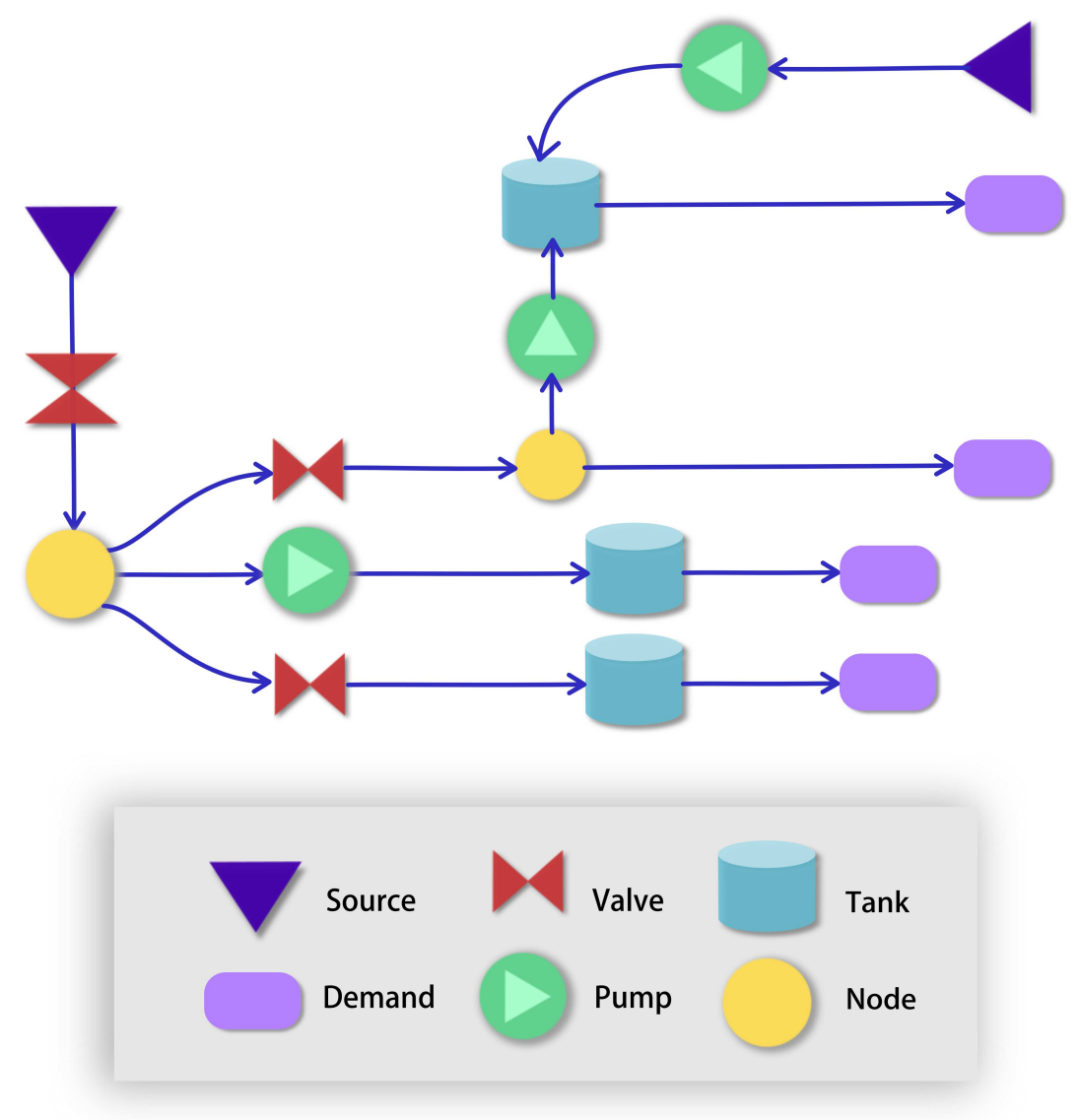

Fig. 2. Example of a basic topology of a generic drinking water transport network. Notice the interaction of the main constitutive elements shown here: sources supply water to the system by means of pumps or valves, depending of the nature of the particular source (superficial or underground). Water is moved by using manipulated actuators in order to fill detention tanks and/or supply water to demands sectors.

where $q_{\text {in }}^{j n}(k)$ denotes the manipulated inflows from the $j$-th element to the $n$-th tank, and $q_{\text {out }}^{n h}(k)$ denotes the manipulated outflows from the $n$-th tank to the $h$-th element (which includes the demand flows as outflows). Moreover, $\Delta t$ corresponds with the sampling time and $k$ the discrete-time instant. The physical constraint related to the range of admissible storage volume in the $n$-th tank is expressed as

$$
\underline{v}_{n} \leq v_{n}(k) \leq \bar{v}_{n}, \quad \text { for all } k,
$$

where $\underline{v}_{n}$ and $\bar{v}_{n}$ denote the minimum and the maximum admissible storage capacity, respectively. Notice that $\underline{v}_{n}$ might correspond with an empty tank; in practice this value can be set as nonzero in order to maintain an emergency stored volume.

For simplicity, the dynamic behavior of these elements is described as a function of volume. However, in most cases the measured variable is the tank water level (by using level sensors), which implies the computation of volume taking into account the tank geometry.

2) Actuators: Two types of control actuators are considered: valves and pumps, or more precisely, complex pumping stations. A pumping station generally contains a number of individual pumps with fixed of variable speed. In practice, it is assumed that the flow through a pumping station is a continuous variable in a range of feasible values. The manipulated flows through the actuators represent the manipulated variables, denoted as $q_{u}$. Both pumping stations and valves have lower and upper physical limits, which are taken into account as system constraints. As in (2), they are expressed as

$$
{\underline{q_{u}}}_{m} \leq q_{u_{m}}(k) \leq{\overline{q_{u}}}_{m}, \quad \text { for all } k,
$$


where ${\underline{q_{u}}}_{m}$ and $\overline{q_{u}}$ denote the minimum and the maximum flow capacity of the $m$-th actuator, respectively. Since this modeling is stated within a supervisory control framework, it is assumed that a local controller is available, which ensures that the required flow through the actuator is obtained.

3) Nodes: These elements correspond to the network points where water flows are merged or split. Thus, nodes represent mass balance relations, modeled as equality constraints related to inflows - from other tanks through valves or pumps - and outflows, the latter being not only manipulated flows but also demand flows. The expression of the mass balance in these elements can be written as

$$
\sum_{j} q_{\mathrm{in}}^{j r}(k)=\sum_{h} q_{\mathrm{out}}^{r h}(k)
$$

where $q_{\text {in }}^{j r}(k)$ denotes inflows from the $j$-th element to the $r$-th node, and $q_{\text {out }}^{r h}(k)$ denotes outflows from the $r$-th node to the $h$-th element. From now on, node inflows and outflows will be denoted by $q_{\text {in }}$ and $q_{\text {out }}$, even if they are manipulated variables (denoted by $q_{u}$ ).

4) Demand Sectors: A demand sector represents the water demand of the network users of a certain physical area. It is considered as a measured disturbance of the system at a given time instant. The demand can be anticipated by forecasting algorithms, which are integrated within the MPC closed-loop architecture. For the cases of study in this paper, the algorithm proposed in [19] is considered. This algorithm typically uses a two-level scheme composed of

(i) a time-series model to represent the daily aggregate flow values, and

(ii) a set of different daily flow demand patterns according to the day type to cater for different consumption during the weekends and holidays periods. Every pattern consists of 24-hourly values for each daily pattern.

The algorithm runs in parallel with the MPC algorithm. The daily series of hourly-flow predictions are computed as a product of the daily aggregate flow value and the appropriate hourly demand pattern. Regarding the daily demand forecast, its corresponding flow model is built on the basis of an ARIMA time-series modeling approach described elsewhere [20]. Then, the structure of the daily flow model for each demand sensor may be written as

$$
y_{p}(k)=-b_{1} y(k-1)-b_{2} y(k-2)-b_{3} y(k-3)-b_{4} y(k-4)-b_{5} y(k-5)-b_{6} y(k-6)-b_{7} y(k-7) .
$$

where the parameters $b_{1}, \ldots, b_{7}$ are estimated based on historical data. The 1-hour flow model is based on distributing the daily flow prediction provided by the time-series model in (5) using an hourly-flow pattern that takes into account the daily/monthly variation as follows:

$$
y_{p h}(k+i)=\frac{y_{\text {pat }}(k, i)}{\sum_{j=1}^{24} y_{\text {pat }}(k, j)} y_{p}(k), \quad i=1, \ldots, 24,
$$

where $y_{p}(k)$ is the predicted flow for the current day $k$ using (5) and $y_{p a t}(k)$ is the prediction provided by the flow pattern with the flow pattern class day/month of the current day. Demand patterns are obtained from statistical analysis.

\section{B. Sewer Networks (SN)}

Sewer are open canals. The Saint-Venant equations, based on physical principles of mass conservation and energy, allow the accurate description of the open-canal flow in sewer pipes [15] and therefore also allow to have a detailed nonlinear description of the system behavior. These partial-differential equations constitutes a nonlinear system, which is in general solved by iterative numerical procedures. For an arbitrary geometry of the sewer pipe, these equations may not have an analytic solution. Notice that these equations describe the system behavior in high detail. However, this level of detail is not useful for 
real-time implementation in an optimal control scheme due to the complexity of obtaining the solution of high computational cost.

Several simplified modeling techniques that deal with RTC of sewer networks have been presented in the literature, see, e.g., [21], [22], [23], [7]. The modeling approaches presented here follow closely the mathematical modeling principles given in [24]. Hence, the sewage system is divided into a set of catchments, each one conceptually represented as a virtual tank, as described in [24], [25].

Using the virtual tank modeling principle and the mass balance conservation law, a sewer network can be decomposed in a set of catchments described by using the elementary models explained below and shown in Figures 3 and 4, to obtain a simpler network. This representation also includes other sewer infrastructure elements such as detention tanks, gates, and weirs (other common sewage system elements such as pumping stations can be easily represented by using the mentioned modeling principles but are omitted here as they are not taken into account in the SN case study considered in this article). The set of elements is presented below. A conceptual scheme is included to describe its operation and also for explaining the mathematical relations and derived equations.

1) Virtual and Real Tanks: Consider that a SN is composed by $n$ tanks, from which $n_{1}$ tanks are virtual and $n_{2}$ are real, with $n=n_{1}+n_{2}$. In the case of virtual tanks, used to model network catchments, the mass balance equation relates the stored volume, the flows in sewers going into and out of the tanks and the rain entering the catchment as follows:

$$
v_{n_{1}}(k+1)=v_{n_{1}}(k)+\Delta t \varphi_{n_{1}} S_{n_{1}} P_{n_{1}}(k)+\Delta t\left(\sum_{j} q_{\text {in }}^{n_{1} j}(k)-\sum_{h} q_{\text {out }}^{n_{1} h}(k)\right),
$$

where $\varphi_{n_{1}}$ corresponds with the ground absorption coefficient of the $n_{1}$-th catchment, $S_{n_{1}}$ is the surface area, $P(k)$ is the rain intensity at each sample with a sampling time $\Delta t$. The manipulated variables of the system, denoted as $q_{u_{m}}$, are the flows through control gates. Tank outflows are assumed to be proportional to the water volume currently stored within the tank, that is,

$$
q_{\text {out }}^{n_{1} h}(k)=\beta_{n_{1}} v_{n_{1}}(k),
$$

where $\beta_{n_{1}}$ is defined as the volume/flow conversion (VFC) coefficient as suggested in [26] by using the linear tank model approach. Notice that this relation can be made more accurate, but more complex, if (8) is considered to be nonlinear (nonlinear tank model approach) or by considering linear models with online parameter estimation [27]. See for example [28], where nonlinear models are identified as a function of inflows and outflows.

Limits on the admissible volume of real tanks are expressed as

$$
0 \leq v_{n_{2}}(k) \leq \bar{v}_{n_{2}}, \quad \text { for all } k,
$$

where $\bar{v}_{n_{2}}$ denotes the maximum volume capacity. As this constraint is physical, it is impossible to send more water to a real tank than it can store. Notice that real tanks without overflow capability have been considered. Virtual tanks do not have a physical upper limit on their capacity. This fact represents the case when sewage level in sewers has reached a limit so that overflow situation or flooding to the street occurs. Hence, when the maximum volume $\bar{v}$ is reached in a virtual tank, the excess volume is redirected to another tank/catchment within the network or to a receiving environment. This phenomenon is known as combined sewer overflow (CSO). This situation implies a new flow path coming from the tank and denoted as $q_{d}$ (referred to as virtual tank overflow), which can be expressed as

$$
q_{d}(k)= \begin{cases}\frac{(v(k)-\bar{v})}{\Delta t} & \text { if } v(k) \geq \bar{v} \\ 0 & \text { otherwise }\end{cases}
$$




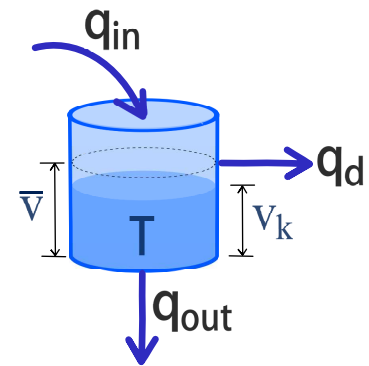

(a) Virtual tank

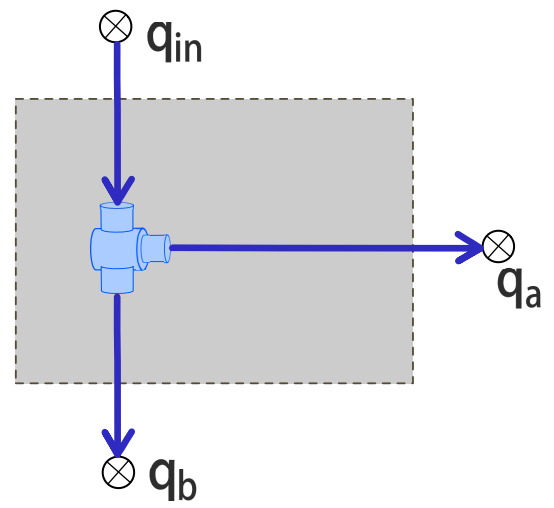

(c) Flow diversion gate

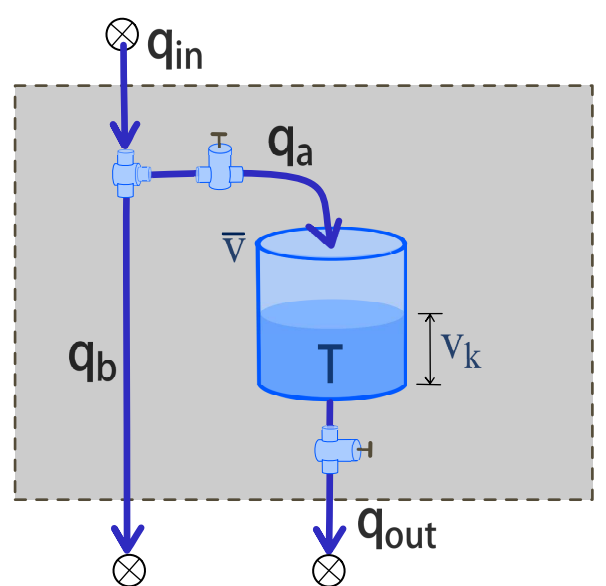

(b) Real tank

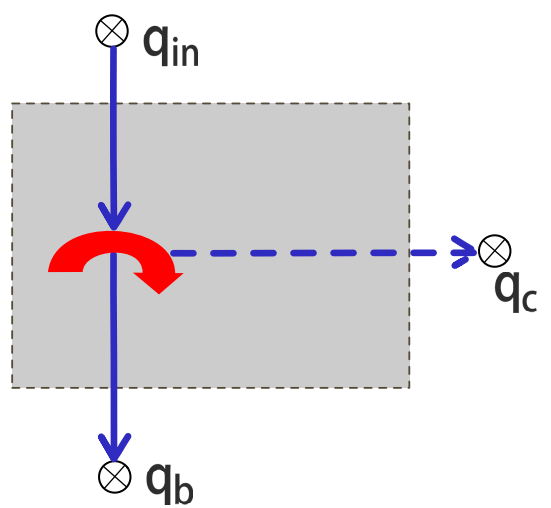

(d) Sewer pipe or weir with single flow

Fig. 3. Conceptual schemes for sewer networks constitutive elements. Top graphs show the different tanks considered and the common way they are connected and configured (using auxiliary elements according to the case). Notice that elements (a) and (b) introduce to the system switching behaviors given when their maximum capacity, namely flow or volume, is achieved.

Thus, outflow of virtual tank is then limited by its maximum volume capacity as follows:

$$
q_{\text {out }}(k)= \begin{cases}\beta \bar{v} & \text { if } \quad v(k) \geq \bar{v} \\ \beta v(k) & \text { otherwise. }\end{cases}
$$

Consequently, considering this expression for tank overflow, the difference equation (7) related to virtual tanks becomes

$$
v_{n_{1}}(k+1)=v_{n_{1}}(k)+\Delta t \varphi_{n_{1}} S_{n_{1}} P_{n_{1}}(k)+\Delta t\left(\sum_{j} q_{\text {in }}^{j n_{1}}(k)-\sum_{h} q_{\text {out }}^{n_{1} h}(k)-q_{d}(k)\right) .
$$




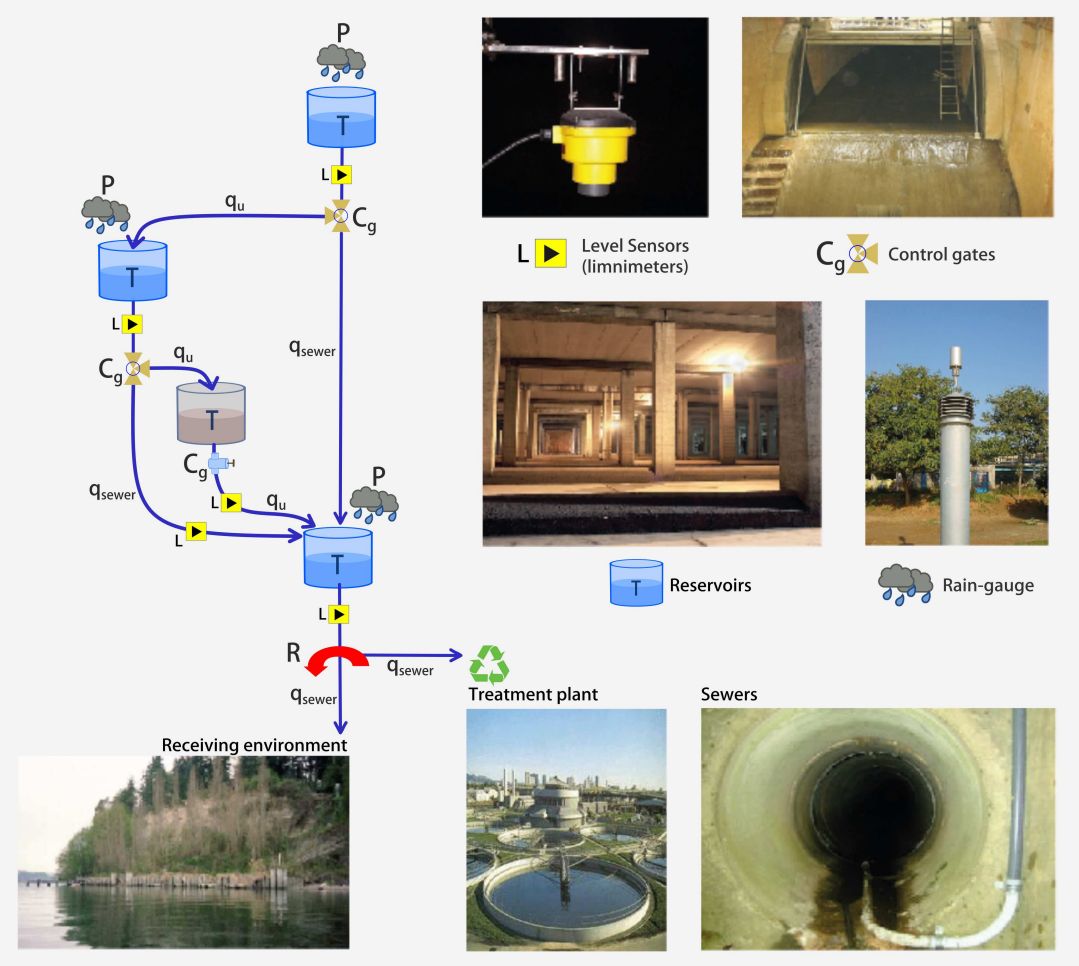

Fig. 4. Simple sewer network conformed by some traditional elements. According to the case, there are different types of sensors depending on the measurements taken. Moreover, actuators may be gates or pumping stations, this latter mainly used when storing sewage into multiplebody tanks with complex emptying strategies. Even the WWTPs are in theirself complex systems, their interconnection with the sewer network allows to determine the way of managing the sewage in order to avoid pollution phenomena, fulfilling one of the common control objectives for these networked systems.

Real detention tanks are closed concrete structures used to store water in rain events. For this reason, both tank inflow and outflow are controlled using gates. Similarly, the admissible flows into and out of the tank are related to the current volume stored in the tank. Tank inflow is constrained by the current sewage volume of the real tank, by its maximum capacity and by tank outflow. Since real tanks are considered with no overflow capabilities, inflow is pre-manipulated by using a flow diversion gate (explained below), what results in the consideration of this component within the modeling of the real tank. In Figure 3 show conceptual schemes of the both virtual and real tanks considered in this article. In order to restrict the value of the manipulated flow $q_{a}^{\star}(k)$ to satisfy the maximum flow condition in the input gate, flow through input link $q_{a}$ is expressed as

$$
\tilde{q}_{a}(k)= \begin{cases}q_{a}^{\star}(k) & \text { if } q_{a}^{\star}(k) \leq q_{\text {in }}(k) \\ q_{\text {in }}(k) & \text { otherwise. }\end{cases}
$$

However, maximum tank capacity also restricts the inflow according to the expression

$$
q_{a}(k)= \begin{cases}\tilde{q}_{a}(k) & \text { if } q_{b}(k)-q_{\text {out }}(k) \leq \frac{\bar{v}-v(k)}{\Delta t} \\ \frac{\bar{v}-v(k)}{\Delta t} & \text { otherwise. }\end{cases}
$$

Finally, tank outflow is given by

$$
q_{\text {out }}(k)= \begin{cases}q_{\text {out }}^{\star}(k) & \text { if } q_{\text {out }}^{\star}(k) \leq \beta v(k) \\ \beta v(k) & \text { otherwise, }\end{cases}
$$

taking into account that $q_{\text {out }}^{\star}$ is also restricted by the maximum capacity of the outflow link, denoted by 
$\bar{q}_{\text {out }}(k)$. Thus, latter expressions lead to the following difference equation for real tanks in sewer networks:

$$
v(k+1)=v(k)+\Delta t\left(q_{a}(k)-q_{\text {out }}(k)\right) .
$$

Notice that the flow through $q_{b}$ corresponds to the mass balance

$$
q_{b}(k)=q_{\text {in }}(k)-q_{a}(k) .
$$

2) Controlled Gates: In sewer networks, gates are used as flow control devices. Depending on the actions they perform, gates can be classified as flow diversion gates, which are used to divert the sewage flow, and detention gates, which are used to stop flow at a certain point in the network. In a real tank, a detention gate is used to control the outflow. Flow diversion gates, shown in Figure 3(c), divert the flow at a junction, controlling flow from one sewer into others. The following equation expresses the mass conservation relation in the element:

$$
q_{\text {in }}(k)=\sum_{j} q_{u}^{j}(k),
$$

where $j$ is an index over all manipulated gate outflows $q_{u}^{j}$, and $q_{\text {in }}$ is the flow arriving the gate.

When this modeling approach is employed, the inherent nonlinear dynamics of the sewer network are simplified by assuming that only flows are manipulated. The physical limits must be included as constraints on system variables (in this case, on the control inputs). For example, variable $q_{u}^{j}$ can never be larger than the tank discharges resulting from the action of gravity on the current volume of water stored in the tank. This constraint is expressed by the inequality

$$
\sum_{j} q_{u}^{j}(k) \leq \beta_{n_{1}} v_{n_{1}}(k)
$$

Usually, the range of actuation is also limited, so the manipulated variable must fulfill

$$
\underline{q}_{u}^{j} \leq q_{u}^{j}(k) \leq \bar{q}_{u}^{j}
$$

where $q_{u}$ denotes the lower limit of the manipulated flow and $\bar{q}_{u}$ denotes its upper limit.

3) Nodes, Weirs and Main Sewer Pipes: These components are passive sewer infrastructure elements. Since the descriptions of their dynamics are relatively close, all of them are presented together in this section. Nodes are points of the network where the sewage can be either propagated or merged. Hence, these elements can be classified as splitting nodes and merging nodes. In the case of a set of $h$ inflows $q_{j}$, with $j=1,2, \ldots, h$, the expression for the node outflow is expressed as

$$
q_{\text {out }}=\sum_{j=1}^{h} q_{j} .
$$

Weirs are passive flow diversion devices built into sewers to derive excess flow from the main sewer (nominal) to another called a spillway. This spillway leads, in some cases, to an overflow discharge point (to a treatment plant or into the receiving environment). Weirs can be seen as splitting nodes having a maximum capacity in the nominal path.

Main sewer pipes are used as connection devices between network constitutive elements (Figure 3(d)). The set of expressions valid to represent the behavior of a weir is

$$
\begin{aligned}
& q_{b}(k)= \begin{cases}\bar{q}_{b} & \text { if } q_{\text {in }}>\bar{q}_{b} \\
q_{\text {in }}(k) & \text { otherwise, }\end{cases} \\
& q_{c}(t)= \begin{cases}q_{\text {in }}(k)-\bar{q}_{b} & \text { if } q_{\text {in }}>\bar{q}_{b} \\
0 & \text { otherwise, }\end{cases}
\end{aligned}
$$

where $\bar{q}_{b}$ is the maximum flow through $q_{b}$ and $q_{\text {in }}$ is the inflow. 


\section{Control-oriented Model}

Considering the set of compositional elements described above, the control-oriented model can be obtained by joining those elements and their corresponding dynamic descriptions. In a general form, the expression which collects all these dynamics can be written as the mapping

$$
x(k+1)=g(x(k), u(k), d(k)),
$$

where $x \in \mathbb{X} \subseteq \mathbb{R}^{n}$ corresponds to the system states, $u \in \mathbb{U} \subseteq \mathbb{R}^{m}$ denotes the system inputs (manipulated variables) and $d \in \mathbb{D} \subseteq \mathbb{R}^{p}$ denotes the system disturbances. $g: \mathbb{R}^{n} \times \mathbb{R}^{m} \times \mathbb{R}^{p} \rightarrow \mathbb{R}^{n}$ is an arbitrary system state function and $k \in \mathbb{Z}_{+}$.

In the case of DWN, (23) is associated to the set of tank expressions in (1). Hence, a control-oriented discrete-time state-space model that can be written as [17]

$$
x(k+1)=A x(k)+B u(k)+B_{p} d(k),
$$

where, in particular, $x$ corresponds to the water volumes $v$ of the $n$ tanks, $u$ represents the manipulated flows $q_{u}$ through the $m$ actuators (pumps and valves), and $d$ corresponds with the vector of $p$ water demands (measured disturbances affecting the system). $A, B$, and $B_{p}$ are the system matrices of suitable dimensions. Notice that, since the system control-oriented model of a DWN does not collect the static dynamics described by DWN nodes in (4), then (24) can be further rewritten as

$$
\begin{aligned}
x(k+1) & =A x(k)+\Gamma \mu(k), \\
{\left[\begin{array}{ll}
E_{u} & E_{d}
\end{array}\right] \mu(k) } & =0,
\end{aligned}
$$

where $\Gamma=\left[\begin{array}{ll}B & B_{p}\end{array}\right], \mu(k)=\left[u(k)^{T} \quad d(k)^{T}\right]^{T}$, and $E_{u}, E_{d}$ are matrices of suitable dimensions. Notice that $(25 \mathrm{a})$ comes from the mass balance in tanks while $(25 \mathrm{~b})$ comes from the network nodes. Also notice that when all the network flows are manipulated, then $A$ is an identity matrix of suitable dimensions.

The case of SN is more complex. As discussed before, the behavior of some elements depends not only on their own state but also on that of other elements (for example weirs). Therefore, although the controloriented model of the SN can be represented, as in the case of DWNs, by a collection of expressions in (12) and (16), some tank inflows and/or outflows can show discontinuous dynamics. Several approaches have been derived for expressing this control-oriented model. In [29], the mixed logical dynamics (MLD) form

$$
\begin{aligned}
x(t+1) & =A x(t)+B_{1} u(t)+B_{2} \delta(t)+B_{3} z(t)+B_{4} d(t), \\
E_{2} \delta(t) & +E_{3} z(t) \leq E_{1} u(t)+E_{4} x(t)+E_{5}+E_{6} d(t),
\end{aligned}
$$

collects in a linear form not only the expressions for all the SN constitutive elements but also the physical and operational constrains of those elements. In (26), $x$ corresponds to the sewage volumes $v$ in the $n$ tanks (real and virtual), $u$ represents the manipulated sewage flows $q_{u}$ through the $m$ actuators (detention and flow diversion gates), and $d$ corresponds to the $p$ rain measurements (after the proper transformation into flow considering the overall network hydrology). Additionally, variables $\delta \in\{0,1\}$ and $z \in \mathbb{R}_{+}$are auxiliary variables associated with the MLD form. It has been shown that the form (26) of the SN model is equivalent to other representations such as the piecewise affine form, the linear complementary form, among others [30]. $A, B_{i}$ (with $i \in\{1, \ldots, 4\}$ ), and $E_{j}$ (with $j \in\{1, \ldots, 6\}$ ) are the system matrices of suitable dimensions (see [14] for further details).

Summarizing, Table I collects all variables related to the control-oriented models for DWN and SN, as well as their descriptions.

\section{Predictive Control ApProAches}

The aim of using MPC techniques for controlling networks related to the UWC is to compute, ahead in time, the input actions to achieve the optimal performance of the network according to a given set of 
TABLE I

VARIABLES OF CONTROL-ORIENTED MODELS AND THEIR DESCRIPTIONS

\begin{tabular}{|c|c|c|c|}
\hline $\begin{array}{l}\text { Type of } \\
\text { variable }\end{array}$ & Symbol & $\begin{array}{c}\text { DWN } \\
\text { description }\end{array}$ & $\begin{array}{c}\text { SN } \\
\text { description }\end{array}$ \\
\hline Systems states & $v(k)$ & tank volumes & real/virtual tank volumes \\
\hline Control inputs & $q_{u}(k)$ & $\begin{array}{l}\text { manipulated flows through } \\
\text { valves and pumps }\end{array}$ & $\begin{array}{c}\text { manipulated flows through } \\
\text { detention/diversion gates }\end{array}$ \\
\hline Measured disturbances & $d(k)$ & water demand & rain inflow \\
\hline
\end{tabular}

control goals. MPC strategies have some important features to deal with complex systems such as DWNs and SNs, namely the amenability to include disturbance forecasts, physical constraints and multivariable system dynamics and objectives in a relatively simple way.

This section describes the main ideas of the global control of water networks within the MPC framework. The predictive control formulation shares some aspects in common for both types of water networks. These main aspects are treated in this section.

\section{A. System Model}

An adequate system model is one of the main ingredients in the design process of an MPC scheme. In fact, the control law is related to the mathematical nature of the system model. In this article, this aspect has been discussed in the modeling section. Hence, (25) corresponds to the mathematical model considered here in the design of MPC controllers for DWNs. Regarding SNs, the equivalent piecewise linear model of and (26), proposed by [31], has been properly considered.

\section{B. System Constraints}

System constraints are given by the physical nature of the variables involved in the modeling process and by some elements present in those networks, for example, merging and/or splitting nodes. In general, these constraints must not be violated due to mass conservation principles or physical restrictions in real elements. Taking into account the flow-based modeling approach discussed in previous sections, models of both DWNs and SNs consider tanks, links/pipes and pumps/valves as some of their compositional elements. This fact implies the determination of hard constraints for their physical limits as follows:

(i) For tank volumetric capacities - network state variables - are limited by

$$
x_{i}^{\min } \leq x_{i}(k) \leq x_{i}^{\max }, \quad \text { for all } k, i \in\{1, \ldots, n\}
$$

where $x_{i}^{\min }$ and $x_{i}^{\max }$ denote the minimum and maximum volume capacity, respectively, given in cubic meters.

(ii) For flows in actuators and in the interconnection links,

$$
\begin{aligned}
& u_{i}^{\min } \leq u_{i}(k) \leq u_{i}^{\max }, \quad \text { for all } k, i \in\{1, \ldots, m\} \quad \text { (manipulated variables) }, \\
& q_{i}^{\min } \leq q_{i}(k) \leq q_{i}^{\max }, \quad \text { for all } k, \quad i \in\left\{1, \ldots, m_{2}\right\} \quad \text { (other links, if any), }
\end{aligned}
$$

where $u_{i}^{\min }$ or $q_{i}^{\min }$ and $u_{i}^{\max }$ or $q_{i}^{\max }$ denote the minimum and the maximum flow capacities, respectively, given in $\mathrm{m}^{3} / \mathrm{s}$. Moreover, $m_{2}$ corresponds with the number of non manipulated links in SNs.

\section{Control Objectives and Cost Functions}

It is possible to use different control objectives for each network of the UWC depending on the operational goals sought by the operators. This section describes the most common control objectives and the resultant multi-objective cost function for each case. Many other criteria can be included by defining the corresponding objective function. 
1) Objectives in DWN: For DWNs, this article considers and discussed the following control objectives [17], [32]:

a) Minimization of water production and transport costs: The main economic costs associated with drinking water production are due to treatment processes, water acquisition or use costs and, most importantly, to electricity costs for pumping. Delivering this drinking water to appropriate pressure levels through the network involves important electricity costs in booster pumping as well as elevation from underground devices. In a specific case, this objective can be mathematically formulated as the minimization of

$$
J_{1}(k) \triangleq\left(\alpha_{1}+\alpha_{2}(k)\right) q_{u}(k),
$$

where $\alpha_{1}$ corresponds to a known vector related to the economic costs of the water depending on the selected water source, and $\alpha_{2}(k)$ is a vector of suitable dimensions associated to the economic cost of the flow through certain actuators (pumps only) and their control cost (pumping). Note the $k$-dependence of $\alpha_{2}$ since the pumping cost has different values according to the variable electric tariffs along a day.

b) Appropriate management of safety water storage: The satisfaction of water demands must be fulfilled at all times. However, some risk prevention mechanisms need to be introduced in the tank management so that, additionally, the stored volume is preferably maintained above certain safety value for eventual emergency needs and to guarantee future water availability. Therefore, this objective may be achieved by minimizing the following expression:

$$
J_{2}(k)= \begin{cases}\left(v(k)-v^{\text {safe }}\right)^{T}\left(v(k)-v^{\text {safe }}\right) & \text { if } v(t) \leq v^{\text {safe }} \\ 0 & \text { otherwise }\end{cases}
$$

where $v^{\text {safe }}$ is a term which determines the safety volume to be considered for the control law computation. This term might appear as unnecessary given the guarantees of the MPC design but, since a trade-off between the other costs and the volumes is present, the controller would tend to keep the lowest possible the tanks water volumes. This fact would reduce the safely of the system to handle unexpected extra demands, such as fire extinction, among others.

c) Smoothing of control actions: Valves must also operate smoothly in order to avoid big transients in the pressurized pipes. This fact could lead to poor pipe condition. The use of a smooth reference changes also helps the lower-level regulator performance. Similarly, water flows requested from treatment plants must have a smooth profile due to plants operational constraints. To obtain such smoothing effect, control signal variation between consecutive time intervals is therefore penalized. The penalty term to be minimized is

$$
J_{3}(k)=\Delta q_{u}(k)^{T} \Delta q_{u}(k),
$$

where $\Delta q_{u}(k) \triangleq q_{u}(k)-q_{u}(k-1)$.

2) Objectives in SNs: The sewer system control problem has multiple objectives with different priority [7]. According to the literature of SNs, the common control objectives for the management of SNs are briefly discussed below in a given order of decreasing priority.

a) Minimization of flooding in streets: In cases of severe rain, wastewater and stormwater of the sewer system can saturate the pipes, flowing to the streets. Given that this situation must be avoided, the related objective can be defined as the minimization of the overflows to the street in main sewers and catchments, that is,

$$
J_{1}(k)= \begin{cases}\left(q(k)-q^{f}\right)^{T}\left(q(k)-q^{f}\right) & \text { if } q(k) \geq q^{f}, \\ 0 & \text { otherwise, }\end{cases}
$$

where $q^{f}$ corresponds with the vector of flooding flows of the involved elements.

b) Minimization of the CSO to the receiving environment: CSO is produced when untreated sewage flows reach a spillway to the receiving environment. This situation must also be avoided, whenever 
possible. At each time instant the following expression must be minimized

$$
J_{2}(k)= \begin{cases}\left(q(k)-q^{\mathrm{pol}}\right)^{T}\left(q(k)-q^{\mathrm{pol}}\right) & \text { if } q(k) \geq q^{\mathrm{pol}}, \\ 0 & \text { otherwise, }\end{cases}
$$

where $q^{\text {pol }}$ is the maximum flow allowed just before releasing sewage to the receiving environment. Notice that this term can be seen as a special case of the first objective where only the overflows going to a receiving environment are taken into account. This allows to have this trade-off between retaining water in the network at cost of possible flooding in streets, or avoiding that flooding but generating pollution.

c) Maximization of the treated sewage: This objective aims at reducing the amount of untreated sewage that is released to a received environment. This is achieved by minimizing the following expression:

$$
J_{3}(k)=\left(q(k)-q^{\mathrm{wwtp}}\right)^{T}\left(q(k)-q^{\mathrm{wwtp}}\right),
$$

where $q^{\text {wwt }}$ is the maximum allowed flow into the WWTP. A secondary purpose of this objective consists in trying to empty detention tanks as soon as possible in order to anticipate future rainstorms. Additionally, this objective indirectly reduces pollution to the environment by means of using in an optimal way the storage capacity of the network and, at the same time, the capacity of the treatment plan.

3) Multi-objective performance function: The multi-objective performance function $\mathcal{J}(k)$ that gathers the aforementioned control objectives, either in the case of DWN or SN can be written as

$$
\mathcal{J}(k)=\sum_{j=1}^{\varphi} \gamma_{j} J_{j}(k),
$$

where a set of $\varphi$ control objectives are considered and, in turn, a multi-objective OOP is stated. The prioritization of the control objectives is performed by using the order of the mathematical cost function associated to each objective, and also a set of appropriate weights $\gamma_{j}$. These weights are selected offline by means of trial and error procedures, taking into account the priority of each objective within the cost function. More sophisticated tuning methodologies for tuning multiobjective control problems based on lexicographic minimizers [2], goal programming [33], or Pareto-front computations [34] may be also considered.

\section{MPC Problem Formulation}

Collecting the parts described in previous subsections, the MPC design follows the traditional procedures presented in [35], [36], [3], which involve solving an optimization problem over a prediction horizon $H_{p}$, where a cost function is minimized subject to a set of physical and operational constraints. Once the minimization is performed, a vector of $H_{u}$ control actions over $H_{p}$ is obtained. Only the first component of that vector is considered and applied to the plant. The procedure is repeated for the next time instant taking into account the feedback measurements coming from the system, following the classic recedinghorizon strategy.

In general terms, the MPC controller design is based on the solution of a open-loop optimization problem (OOP)

$$
\mathcal{V}\left(k, H_{p}\right)=\min \sum_{i=0}^{H_{p}} \sum_{j=1}^{\varphi} \gamma_{j} J_{j}(k+i \mid k),
$$

subject to the system model and the physical and operational constraints, where $H_{p}$ corresponds to the prediction horizon, and index $k$ represents the current time instant while index $i$ represents the time instant along $H_{p}$. Hence, notation $k+i \mid k$ denotes the time instant $k+i$ given $k$. Notice that (36) corresponds with (35) over the prediction horizon.

According to the case, the minimum of $\mathcal{V}\left(k, H_{p}\right)$ is achieved by finding a set of optimal variables which generally correspond with the manipulated variables of the system model but that could include further 
variables of diverse nature. Hence, for a prediction window of length $H_{p}$ and considering $z \in \mathbb{R}^{s H_{p}}$ as the set of $s$ optimization variables for each time instant over $H_{p}$, the multi-objective optimization problem can be formulated as

$$
\min _{\left\{z \in \mathbb{R}^{s H_{p}}\right\}} f(z)
$$

subject to

$$
\begin{aligned}
& H_{1}(z) \leq 0, \\
& H_{2}(z)=0,
\end{aligned}
$$

where $f(z)$ comes from the manipulation of (36). Moreover, $H_{1}(z)$ and $H_{2}(z)$ are vectors of dimensions $r_{i} H_{p} \times 1$ and $r_{e} H_{p} \times 1$, respectively, containing the constraint functions. Here, $r_{i}$ is the number of inequality constraints and $r_{e}$ is the number of the problem equality constraints. Notice that (37b) and (37c) gather all problem constraints including those from the system model, the physical restrictions of its variables and the operational and management constraints.

Assuming that the OOP (37) is feasible for $z \in \mathbb{R}^{s H_{p}}$, there exists an optimal solution given by the sequence

$$
z^{*} \triangleq\left(z^{*}(0 \mid k), z^{*}(1 \mid k), \ldots, z^{*}\left(H_{p} \mid k\right)\right)
$$

and then the receding horizon philosophy sets [35]

$$
z_{\mathrm{MPC}}(x(k)) \triangleq z^{*}(0 \mid k)
$$

and disregards the computed inputs from $k=1$ to $k=H_{p}$, repeating the whole process at the following time step. Equation (39) is known as the MPC law.

Therefore, the MPC problem formulation in DWNs and SNs gives the expressions for each of the problem parts described above. Thus, mapping (23) must be replaced by the system modeling in (25) or in (26) when treating a DWN or a SN, respectively. Finally, constraints in (37b) and (37c) are conveniently expressed taking into account the type of network and its constitutive components, for example, constraints in (25b) must be included when a DWN is considered. Similarly, constraints in (26b) are taken into account for MPC problems in SNs. In both cases, constraints (2) and (3) are always included. In order to manage the uncertainty of the system disturbances over the prediction horizon, a suitable approach is the stochastic paradigm, which includes explicit models of uncertainty/disturbances in the design of control laws and by transforming hard constraints into probabilistic constraints. As reviewed in [37], the stochastic approach is a classic one in the field of optimization, a renewed attention has been given to the stochastic programming [38], as a powerful tool for robust control design, leading to the Stochastic MPC and specially to the Chance-Constrained MPC (CC-MPC) [39].

\section{Application Results: Barcelona (Spain) Networks}

In this section, some relevant results obtained from the MPC application to the global control of real water network systems in Barcelona (Spain) are presented and briefly discussed. The case studies have been implemented using two software tools developed jointly by the authors' team and the AGBAR and CLABSA companies in Barcelona. These tools are CORAL (for SNs), which is described in [40], and PLIO (for DWNs), described in [18], [27].

The optimization method used by the software tools to solve the resulting optimization problems (37) is a generalized reduced gradient search, first suggested in [41], implemented in the CONOPT solver as part of the GAMS library, which can cater for the nonlinear performance index and constraints. It starts by finding a feasible solution; then, an iterative procedure follows, which consists of $(i)$ finding a search direction, through the use of the Jacobian of the constraints, the selection of a set of basic variables and the computation of the reduced gradient; (ii) performing a search in this direction, through a pseudo-Newton 
process; all until a convergence criterion is met. A description of the algorithm and its implementation may be found in the GAMS solver manuals and deeply reported in [42].

The mathematical models have been obtained by using the modeling methodologies described in this manuscript. Real data collected from the SCADA associated to the Barcelona drinking water and sewer network have been used according to the case. For the case of the DWN, this real data corresponds with the water demand of the network users during several years and with the information of performance of the local controllers at the network actuators (valves and pumping stations). On the other hand, real data from the SN corresponds with measurements of rain sensors during several years. The sewage system has been simulated by using a high-fidely model implemented in MOUSE and developed by CLABSA company. On the other hand, the DWN has been simulated with a detailed SIMULINK model, which has been validated by AGBAR company against their historic data.

\section{A. Results with the Barcelona DWN}

Using the modeling methodology discussed above, a control-oriented model for the Barcelona complete transport network has been built; see Figure 5. This model considers 63 storage tanks (states), three surface sources and six underground sources, 79 pumps, 50 valves, 18 nodes and 88 demands (disturbances). Using this model, the control strategies for the network actuators are obtained. In this case study, the prediction horizon is 24 hours, due to the daily periodicity of demands and operation. Regarding the value of $H_{u}$, it has been set to be equal to $H_{p}$, following the operational needs of the DWN management. A demand forecast during this horizon is provided by a demand system based on time series techniques described in the modeling section. [17], [19].

Results obtained by using the designed MPC control are compared with those obtained employing the current local control approach. The local control is based on PIDs, whose objective is to maintain the water level in the tanks inside pre-established bounds, which might vary during the day in order to take into account the demand variation by pumping more or less water. Notice that the mentioned comparison is performed between the performance reached by the local PID controller already in place and tuned by the company experts, and the global (supervisory) MPC controller providing optimal set-points to the currently existing PID control loops. Basically, it is a comparison of loops with and without supervisory control. On the other hand, centralized and decentralized control approaches are not in the scope of this manuscript. However, comparisons and discussions in that sense over the Barcelona DWN case study have been already carried out [43], [44].

Table II summarizes the obtained control results in terms of performance (water and electrical cost) over four days of typical demand. The water supplied for these four days is shown in Figure 6. In this table, the performance indices representing costs are given in economic units (e.u) instead of a currency due to confidentiality restrictions.

TABLE II

Closed-LOOP PERFormanCE RESUlts (ALL VALUES IN E.U.)

\begin{tabular}{lcccccc}
\hline $\begin{array}{l}\text { Demand } \\
\text { Episodes }\end{array}$ & Water & $\begin{array}{c}\text { Current Control } \\
\text { Electricity }\end{array}$ & Total & Water & $\begin{array}{l}\text { MPC Control } \\
\text { Electricity }\end{array}$ & Total \\
\hline $2007-07-23$ & 514 & 257 & 770 & $268(-48 \%)$ & $229(-11 \%)$ & $497(-55 \%)$ \\
$2007-07-24$ & 508 & 273 & 781 & $339(-33 \%)$ & $231(-15 \%)$ & $560(-37 \%)$ \\
$2007-07-25$ & 519 & 251 & 770 & $317(-39 \%)$ & $228(-9 \%)$ & $545(-41 \%)$ \\
$2007-07-26$ & 537 & 246 & 783 & $324(-40 \%)$ & $229(-7 \%)$ & $553(-41 \%)$ \\
\hline
\end{tabular}

From Table II, it can be noticed that

(i) MPC produces an improvement in the reduction of water costs, between the $30 \%$ and the $50 \%$ with regard to the current control with fixed real flows since the optimizer can maximize the water source 


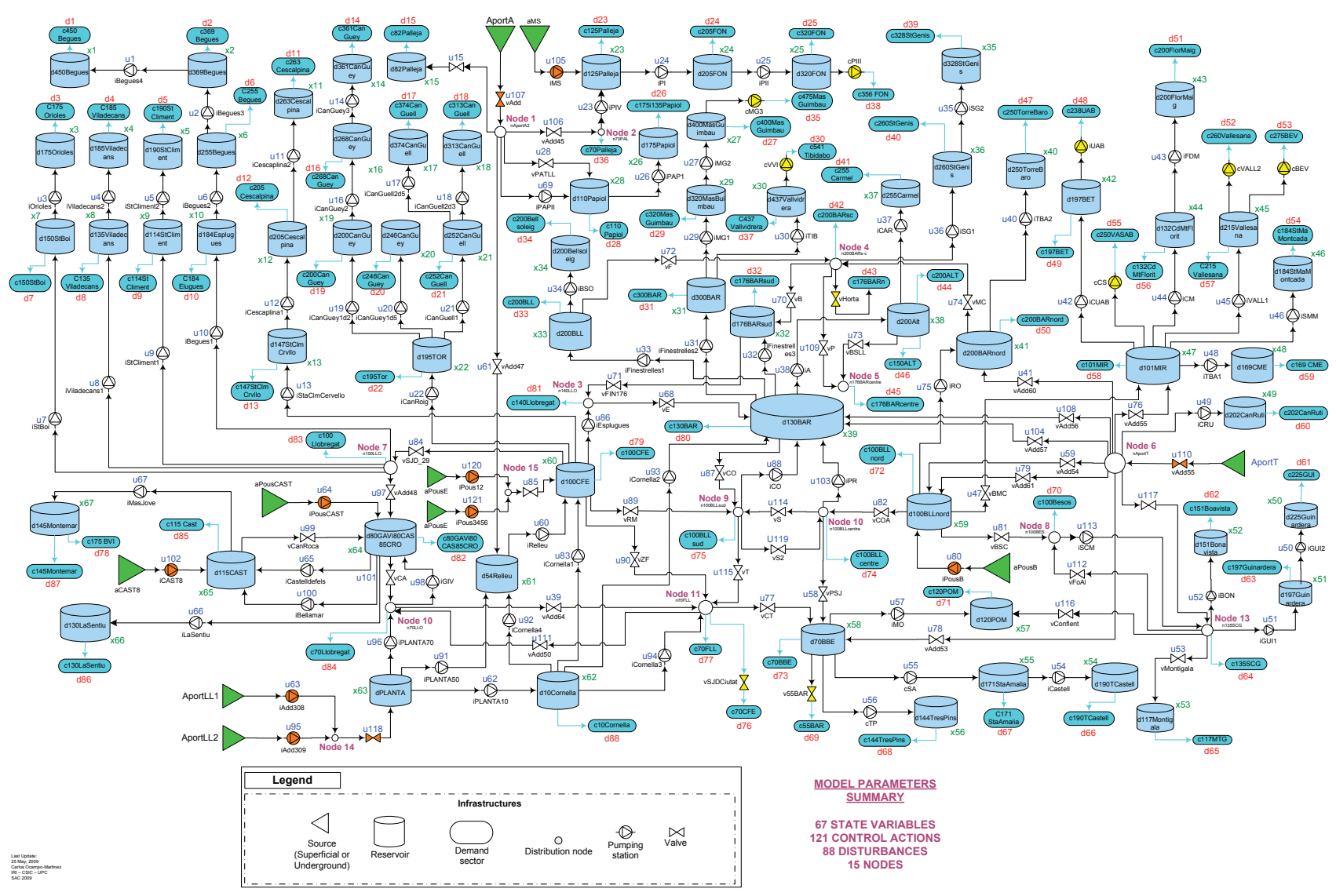

Fig. 5. The Barcelona DWN is managed by the AGBAR water company. It supplies drinking water to Barcelona city and its metropolitan area. The main sources of water are the Ter and Llobregat rivers, which are regulated at their head by some dams with an overall capacity of $600 \mathrm{hm}^{3}$. Currently, there are four drinking water treatment plants (WTP): the Abrera and Sant Joan Despí plants, which extract water from the Llobregat river, the Cardedeu plant, which extracts water from Ter river, and the Besòs plant, which treats the underground flows from the aquifer of the Besòs river. There are also several underground sources (wells), which can provide water through pumping stations. Those different water sources currently provide a flow of around $7 \mathrm{~m}^{3} / \mathrm{s}$. The most important sources in terms of capacity are Sant Joan Despí and Cardedeu. The maximum flow that can be taken from the first is about $5 \mathrm{~m}^{3} / \mathrm{s}$, while from the second is about $7 \mathrm{~m}^{3} / \mathrm{s}$. The water price from each source is different depending on water treatments and legal extraction canons.

contribution, if possible. However, this is not always possible due to legal and contractual reasons not related to the network characteristics (operational limits of actuators and tanks).

(ii) MPC minimizes the electrical costs by pumping as much as possible during the cheapest time period (typically during nights).

Figure 6 shows the evolution of the flow from all sources when MPC is used. Figure 7 compares the operation of some representative pumping stations when the current control - the control strategy currently used by the management company - and MPC are used. Finally, Figure 8 shows the volume evolution of some network tanks, as well as their maximum and safety volumes when each of these control strategies are used.

\section{B. Results with the Barcelona SN}

The city of Barcelona has a combined sewage system (CSS) of approximately $1697 \mathrm{~km}$ length in the municipal area plus $335 \mathrm{~km}$ in the metropolitan area, but only $514.43 \mathrm{~km}$ are considered as the main sewer network. It is worth to notice that Barcelona has a population which is around 1.59 million inhabitants on 

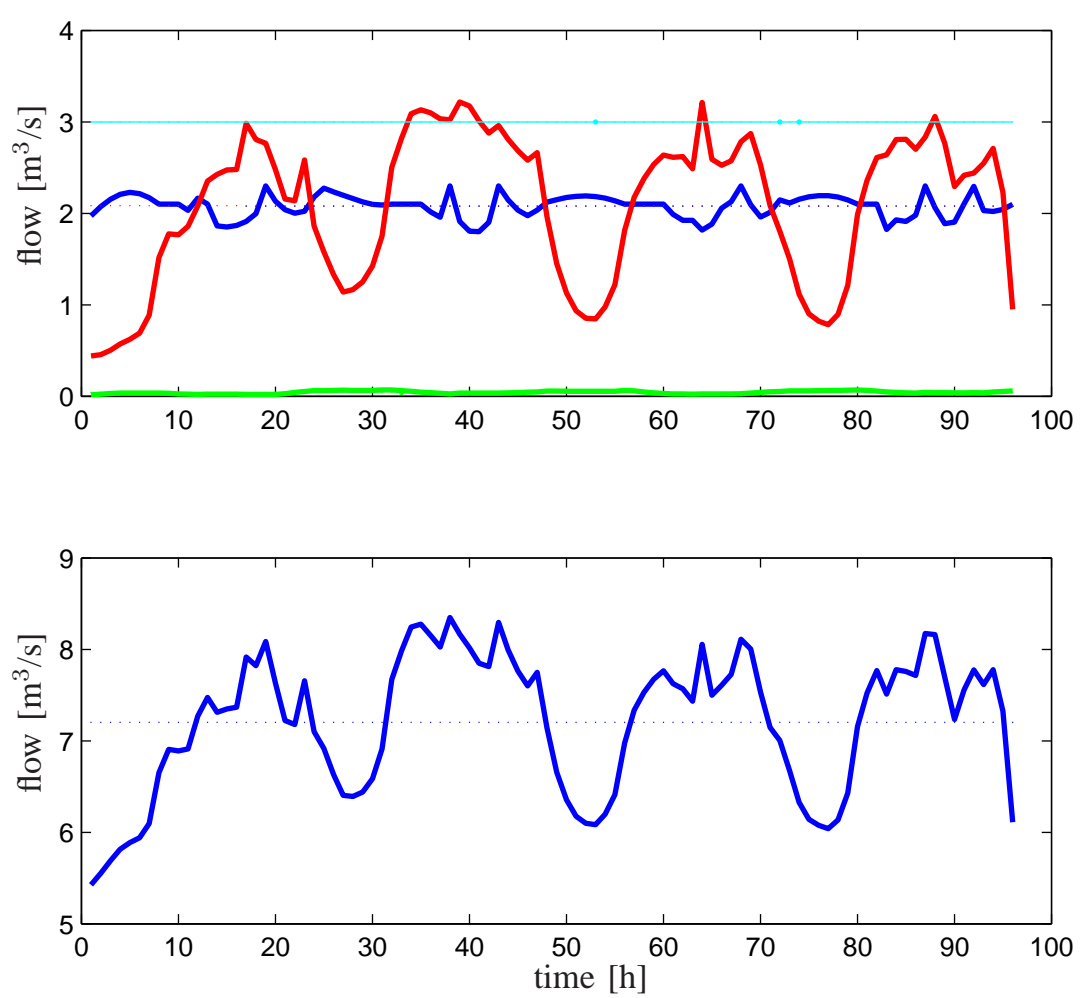

Fig. 6. Inflows from the network sources. In the top graph the water supplies are shown in red for the Ter river, in blue for the Sant Joan Despí superficial source, in cyan for the Sant Joan Despí underground, and in green for the Abrera treatment plant. In the bottom graph the sum of all flows and its average is shown. The mean flow from Llobregat source is about $5 \mathrm{~m}^{3} / \mathrm{s}$, while the rest of water needed to satisfy the total demand is taken from Ter and Abrera sources. The water flow from underground sources is penalized in order to avoid their over-exploitation. In fact, these sources are rarely used.

a surface of $98 \mathrm{~km}^{2}$, approximately. This fact results in a very high density of population. Additionally, the yearly rainfall is not very high $(600 \mathrm{~mm} /$ year), but it includes heavy storms (up to $90 \mathrm{~mm} / \mathrm{h}$ ) typical of the Mediterranean climate that can cause a lot of flooding problems and CSO to the receiving environment. CLABSA is the company in charge of the sewage system management in Barcelona. Their remote control system is in operation since 1994, which includes sensors, regulators, remote stations, communications and a control center. Nowadays, the urban drainage system contains 21 pumping stations, 36 gates, 10 valves and 8 detention tanks, which are regulated in order to prevent flooding and CSO. The remote control system is equipped with 56 remote stations, including 23 rain-gauges and 136 water-level sensors. These latter elements provide real-time information about rainfall and water levels into the sewage system. All the information is centralized at the control center through a SCADA system. The regulated elements - pumps, gates and detention tanks - are currently controlled locally, that is, they are handled from the remote control center according to the measurements of sensors connected only to local stations.

From the whole sewer network of Barcelona, this article considers a portion that is representative of the main phenomena and the most common characteristics of the entire network. For this representative portion, shown in Figure 9, a calibrated and validated model of the network is available. This model has been obtained by using the virtual modeling methodology and rain-gauge data corresponding to an interval of several years.

Using this model, an MPC controller is designed to provide the set-points for the network actuators (local control loops). The corresponding $H_{p}$ is 30 minutes (six samples), with a sampling time of five minutes. A rain forecast during this horizon may be provided by an external rain forecasting system based 

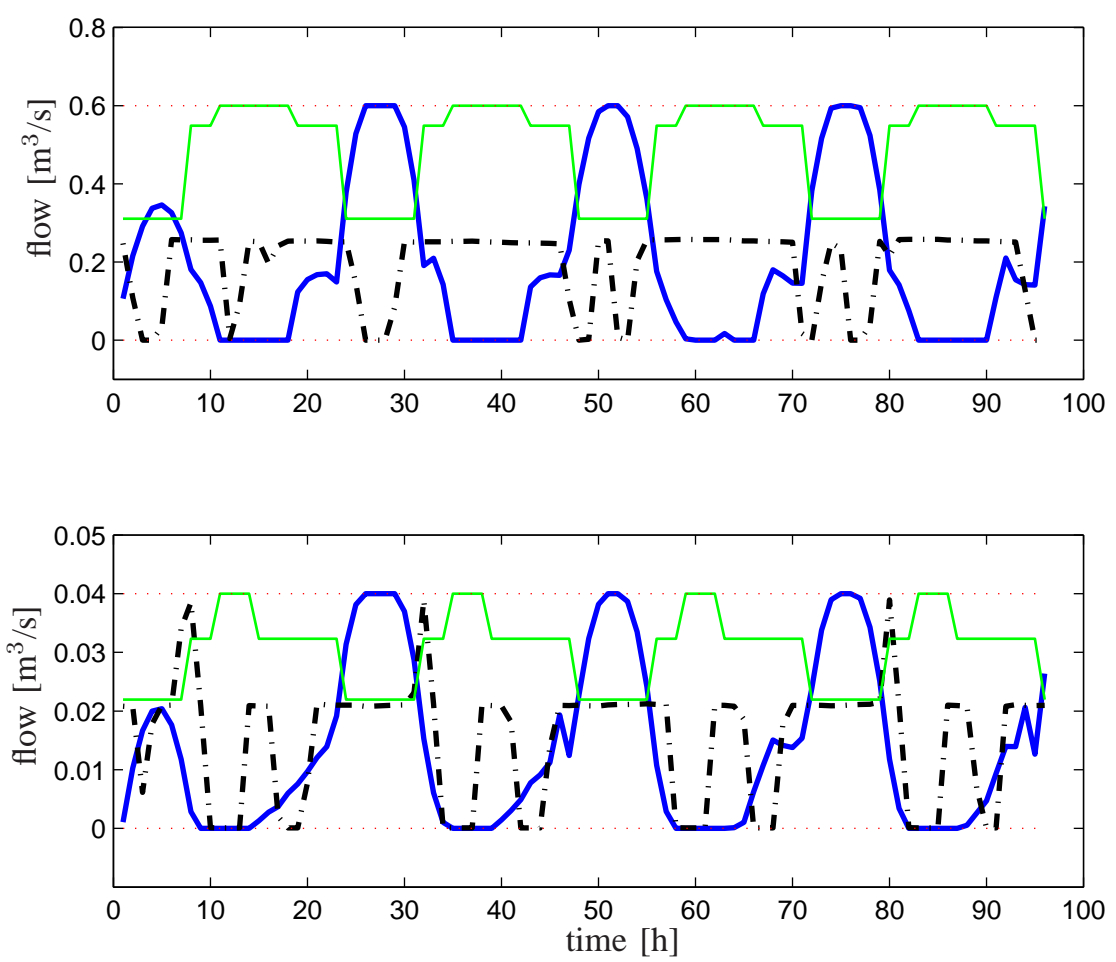

Fig. 7. Electrical fee effects on pumps operation. In both graphs the scaled electric cost is shown in green and the real flow, which corresponds with data from the real actuator manipulation performed by the company, is shown in dotted-dashed black line. Moreover. the optimized flow determined by the MPC controller is shown in blue. The top graph corresponds with the outflow from Finestrelles pumping station, while the bottom graph shows the outflow from Santa Coloma Cervelló pumping station. When MPC is considered, it can be noticed that, pumping stations work during the time interval with cheapest economic cost, if possible. For instance, the flow pumped by Santa Coloma Cervelló pumping station decreases during those periods where the economic cost is not minimal. In contrast, there is not enough flow from Finestrelles pumping station if water is only pumped during the cheapest period of economic costs. Hence, this pumping station must pump water during other periods but the flow rate is lower.

on a meteorological radar, if available, or it may be computed internally using a sample-hold assumption [45].

To compare the performance of the current control strategy based on local controllers with the designed MPC strategy for global management, three different real rain scenarios are considered:

a) Rain scenario 1 (05/01/2006): This is a common winter rain occurred in Barcelona (approximately a 2-month average return period). It is neither very intense nor very long. The maximum intensity occurs in rain gauge $P_{11}$ (see Figure 9), with $49.2 \mathrm{~mm} / \mathrm{h}$, and its duration is about 3 hours. This rain does not cause flooding, so the interest for the test is to avoid CSO spills.

b) Rain scenario 2 (12/09/2006): This is a common summer rain occurred in Barcelona (approx. 1 -year return period). It is intense and longer. The maximum intensity occurs in rain gauge $P_{3}$ (see Figure 9), with $128.4 \mathrm{~mm} / \mathrm{h}$, and its duration is about 3 days but with periods of no rain. This rain may cause flooding if the management of detention tanks is not appropriate, so the interest for the test is to manage flooding and also to avoid CSO spills.

c) Rain scenario 3 (31/07/2002): This is a short and very intense rain. It has an average return period of about eight years. This rain causes flooding. The main performance expected is during the first hours of the event control devices must be managed so that flooding is minimized and, after the rain event, the CSO spill are highly minimized.

Figure 10 shows that more volume of water is treated by the WWTP when MPC is used, while Figure 11 shows the comparison of CSO volumes in the rain scenario 3. The global management reduces significantly 

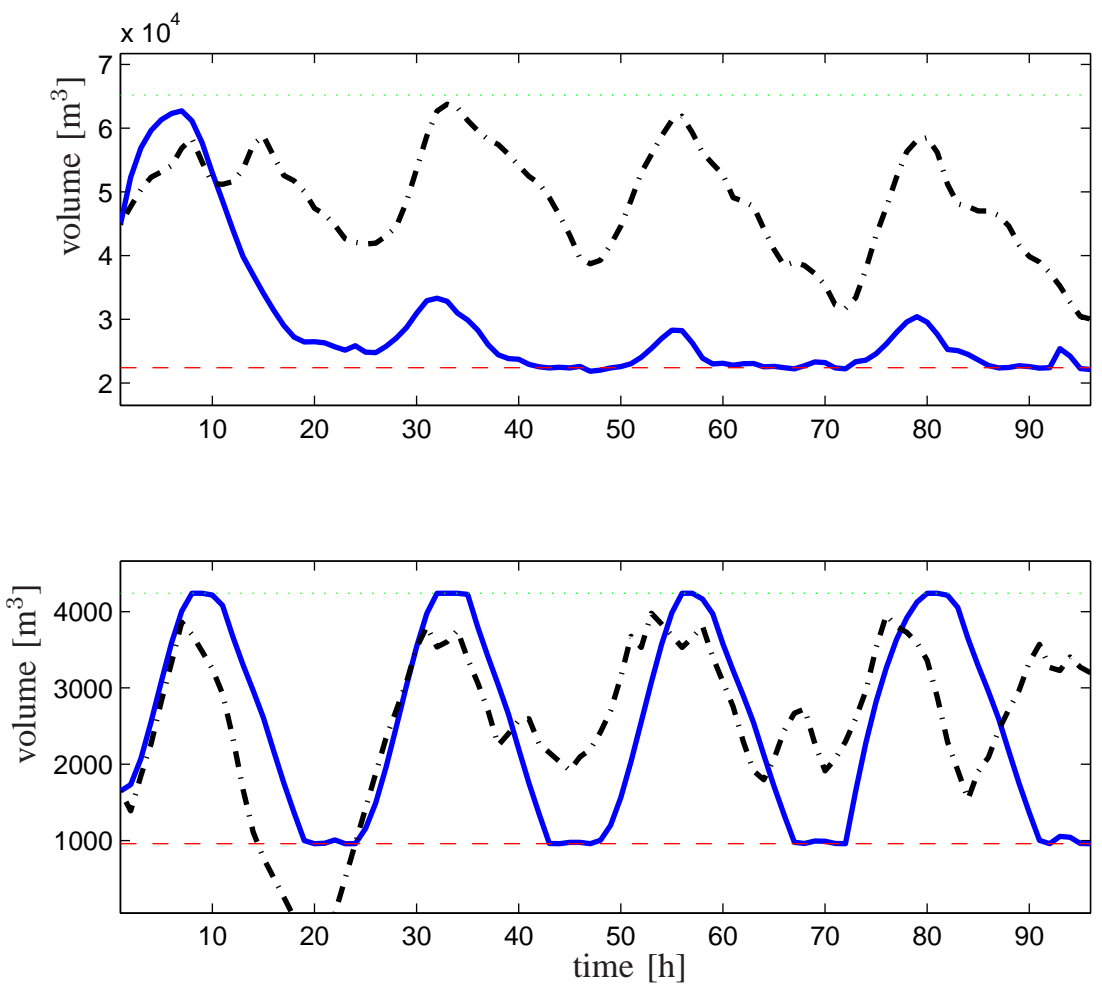

Fig. 8. Volume evolution of some tanks. In both graphs, the real volume is shown in dotted-dashed black, the optimized volume is show in blue, and the penalization volume is shown in dashed red. The top graph corresponds with the the tank d200ALT, where the MPC controller makes the volume lower than the real operation performed by the management company. This fact yields in less economic costs of water transport while decreasing the system safety against failures. The bottom graph corresponds to the tank d70BBE, where the volume never violates the constraints imposed by the MPC controler, in contrast with the case of the real data.

TABLE III

CLOSED-LOOP PERFORMANCE RESULT FOR SOME RAIN EPISODES (ALL VALUES IN CUBIC HECTOMETERS)

\begin{tabular}{lcccccc}
\hline $\begin{array}{l}\text { Rain } \\
\text { Episodes }\end{array}$ & Flooding & $\begin{array}{c}\text { Current Control } \\
\text { Pollution }\end{array}$ & Treated W. & Flooding & $\begin{array}{c}\text { MPC Control } \\
\text { Pollution }\end{array}$ & Treated W. \\
\hline $05 / 01 / 2006$ & 0 & 203 & 77 & 0 & $167(-17 \%)$ & $116(33 \%)$ \\
$12 / 09 / 2006$ & 5662 & 740 & 352 & $4072(-28 \%)$ & $670(-9 \%)$ & $404(12 \%)$ \\
$31 / 07 / 2002$ & 5553 & 643 & 144 & $5436(-2 \%)$ & $588(-8 \%)$ & $198(27 \%)$ \\
\hline
\end{tabular}

the volume of CSO in this scenario. It can be noticed that the WWTP operational constraints are satisfied when the global control is used since they are imposed as constraints in the MPC strategy.

Table III presents the results obtained with the different rain scenarios using the current local control strategy and the global control one based on MPC. Looking at these results, the following observations can be drawn:

(i) In terms of the water volume treated by the WWTP, the global control strategy always outperforms the local control in all the considered scenarios.

(ii) The CSO spill released to the sea is significantly reduced by the global control in all scenarios.

(iii) Flooding is also reduced by the global control strategy based on MPC compared to the local control strategy, although the rain scenarios 12/09/2006 and 31/07/2002 still cause some flooding due to limitations on the infrastructure. 


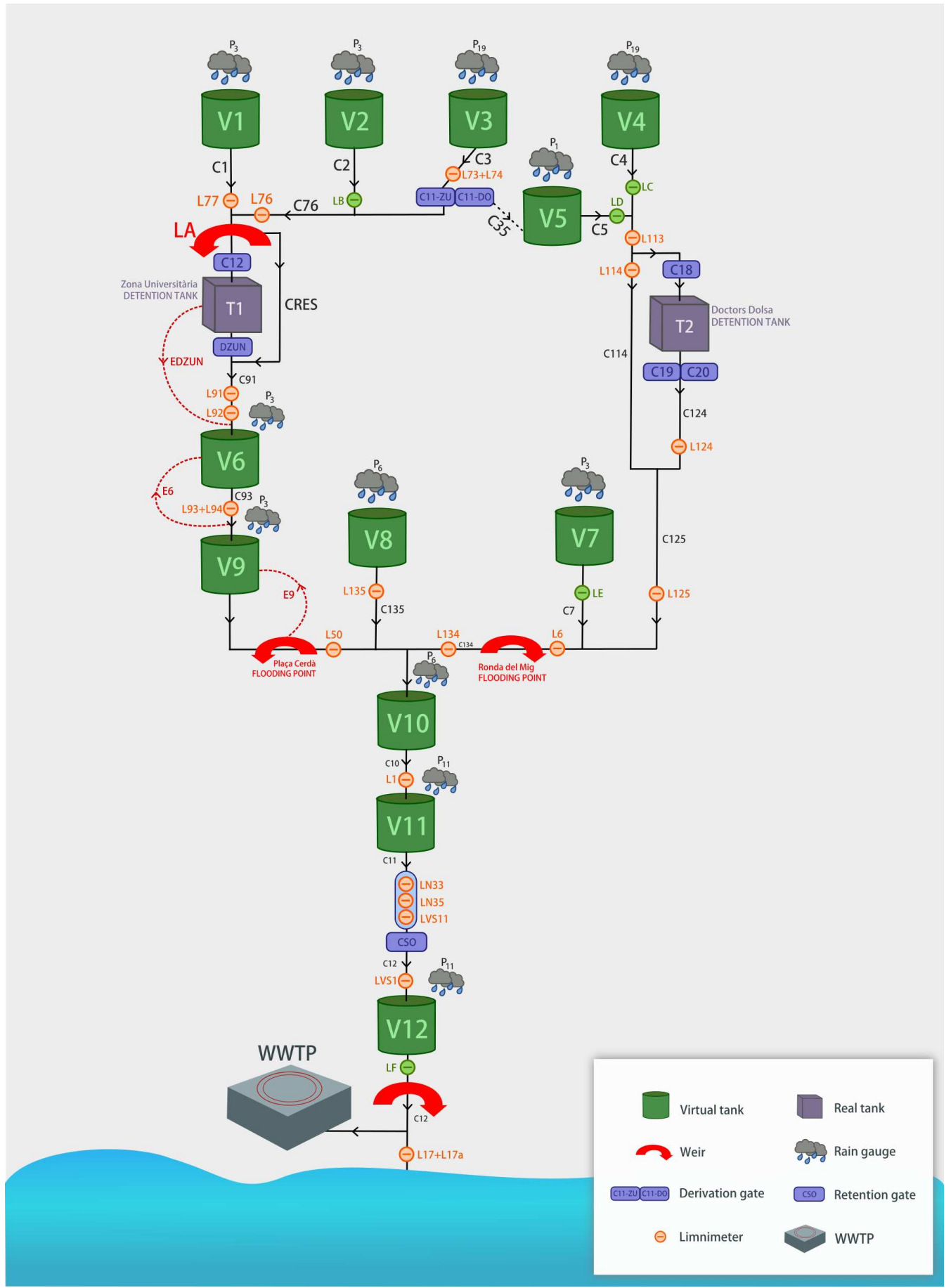

Fig. 9. The considered Barcelona Test Catchment (BTC) has two detention tanks: Zona Universitaria Detention Tank $\left(T_{1}\right)$ and Doctors Dolsa Detention Tank $\left(T_{2}\right)$. Additionally, one large sewer - marked as CSO sewer - with an associated detention gate, is used as additional storage capacity. This procedure is called in-line detention. Gates operating with global control are the detention ones at the output of detention tanks $\left(C_{15}\right.$ and $\left.C_{19}\right)$, the in-line detention gate (CSO) and the flow diversion gate $\left(C_{11}\right)$, which connects the two detention tanks. Eleven measurement points are considered for flooding control in the case of the global control strategy. A waste water treatment plant (WWTP) with a maximum treatment capacity of $2 \mathrm{~m}^{3} / \mathrm{s}$ is located to the end of the BTC. Flows to the WWTP which are bigger than this maximum value are released to the sea, generating CSO. Using the virtual tank approach, the BTC model has 12 state variables corresponding to the volumes in the 12 tanks (two real, ten virtual), four control inputs, corresponding to the gates and five measured disturbances corresponding to measurements of rain precipitation at the sub-catchments of the BTC.

\section{CONCLUSIONS}

The increasing use of advanced information and communication techniques to manage water systems contributes, to a great extent, to achieving environmental and social goals in several fields (see, for 


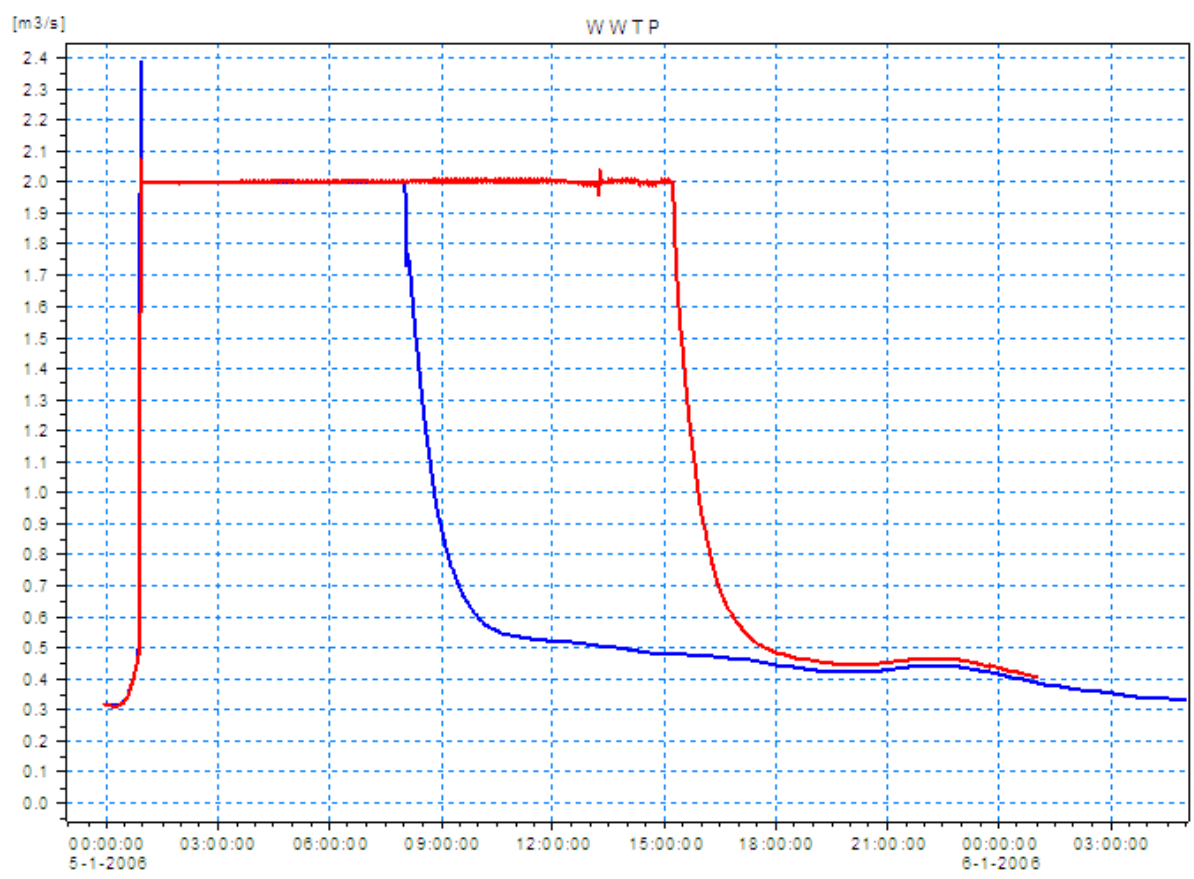

Fig. 10. Comparison of WWTP volume in local and global control, shown in blue and red, respectively. It can be noticed that the WWTP is used for longer time at the maximum capacity in global control than when only local control is used, reducing the pollution to the sea.

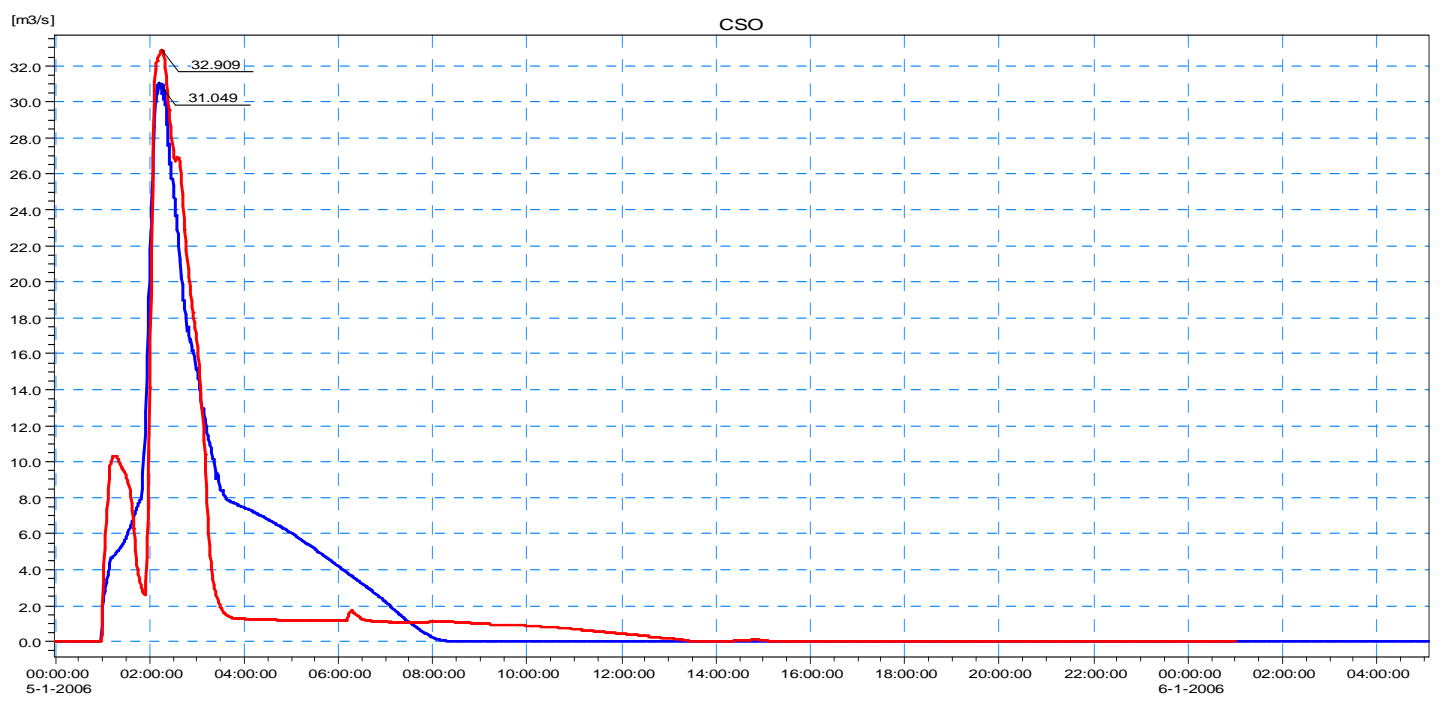

Fig. 11. Comparison of the CSO volume to the sea in local and global control, shown in blue and red, respectively. It can be observed that the global control reduces significantly the volume of CSO (pollution to the sea) in this scenario compared to the local control. This improvement is achieved thanks to the better usage of the on-line retention capacity of the network.

instance, [46]). This article shows how the concepts of MPC can be used to efficiently solve complex management problems in real systems of the urban water cycle. Particularly, this control technique allows to consider different issues on the behavior of these networked systems and to cope with different intrinsic characteristics that can not be treated by using other control strategies.

The different intrinsic characteristics of drinking water networks and sewer networks have been described and appropriate mathematical solutions to tackle them have been presented. Similarly, realistic operational goals of drinking water networks and sewer networks have been outlined and modeled. The article shows the results obtained by applying the MPC with the previously described approaches in two realistic cases taken from the corresponding networks in Barcelona. 


\section{ACKNOWLEDGements}

This work has been partially supported by Spanish research projects WATMAN (DPI2009-13744) and SHERECS (DPI2011-26243), both from the Science and Innovation Ministry, the DGR of Generalitat de Catalunya (SAC group Ref. 2009/SGR/1491), and the European Project iSENSE (FP7-ICT-2009-6270428). The authors thank AGBAR and CLABSA for their technical support and for providing data and information of the cases of study treated in this article. 


\section{Sidebar S1: SofTWARE TOOL FOR MPC DESIGN OF DWNS}

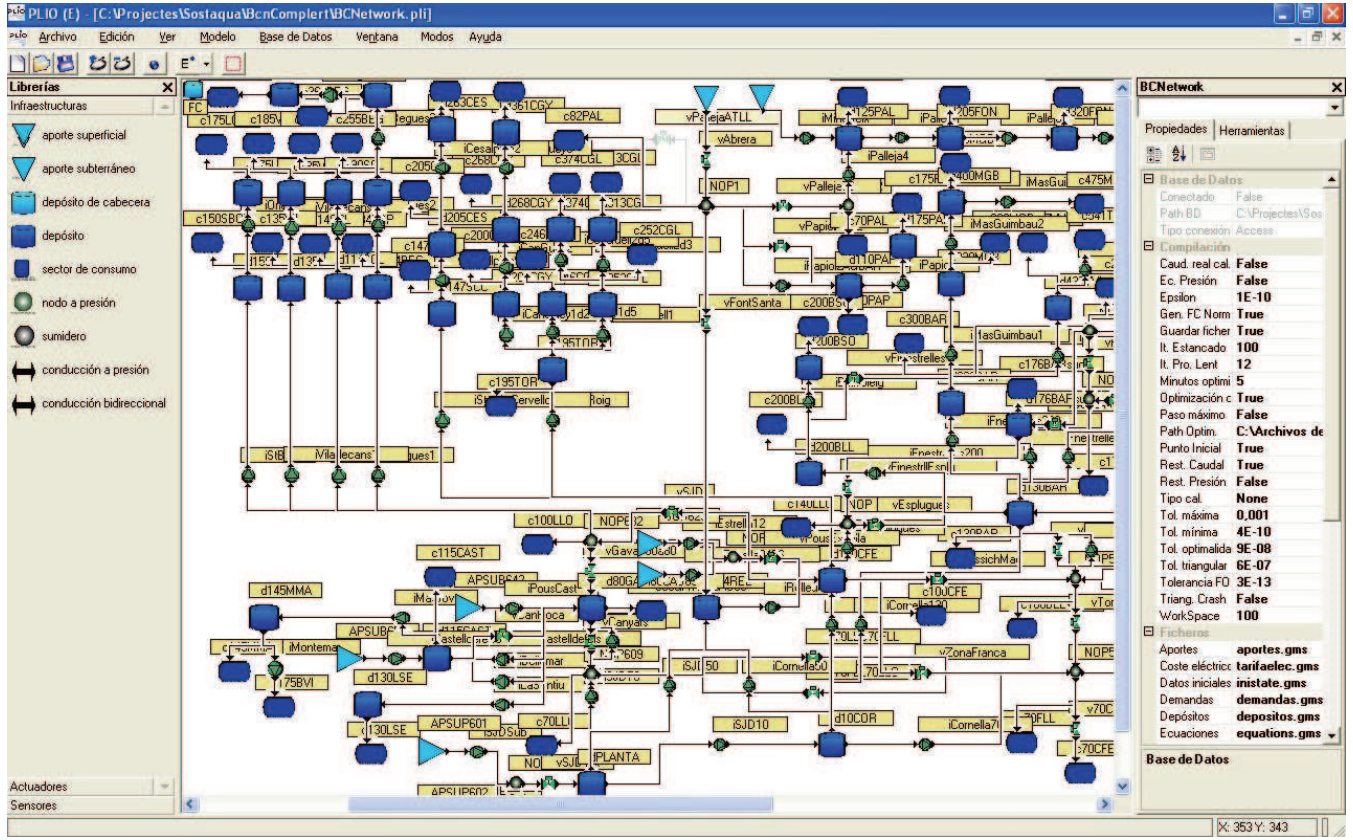

Fig. 12. PLIO interface corresponding to the model manager module than allows creating/updating the model of the water network in a user friendly way.

A general-purpose decision support tool has been developed to allows the user to implement opti$\mathrm{mal} /$ predictive control techniques in large-scale drinking water systems [18]. The tool has been called PLIO. An important feature of PLIO compared to other existing tools is the application of a unified approach to the complete drinking water system including supplies, production, transport and distribution and, therefore pressurized and open-channel dynamics, simultaneously. The modeling and predictive control problem solution algorithm in PLIO are designed for real-time decision support, in connection with a supervisory control and data acquisition system. The hydraulic modeling relies on simple, but representative enough dynamic equations whose parameters are recalibrated on-line using recursive parameter estimation and real data obtained from sensors in the network. Demand forecast models, based on time series analysis, are also dynamically updated. The real-time calibration using recursive parameter estimation methods contributes to dealing with hydraulic uncertainty. This modeling choice, as well as the optimization method selection allows PLIO to deal with very large scale systems. Another distinguishing feature is its capability to accommodate complex operational goals. PLIO was developed jointly by the AGBAR Group and SAC (Advanced Control Systems Group) at UPC (Universitat Politècnica de Catalunya) and CSIC (Spanish National Research Council). Currently, PLIO is in the process of becoming a commercial product Aqualogy AquaAmbiente S.A. 


\section{Sidebar S2: SofTwARE TOOL FOR MPC DESIGN OF SNS}

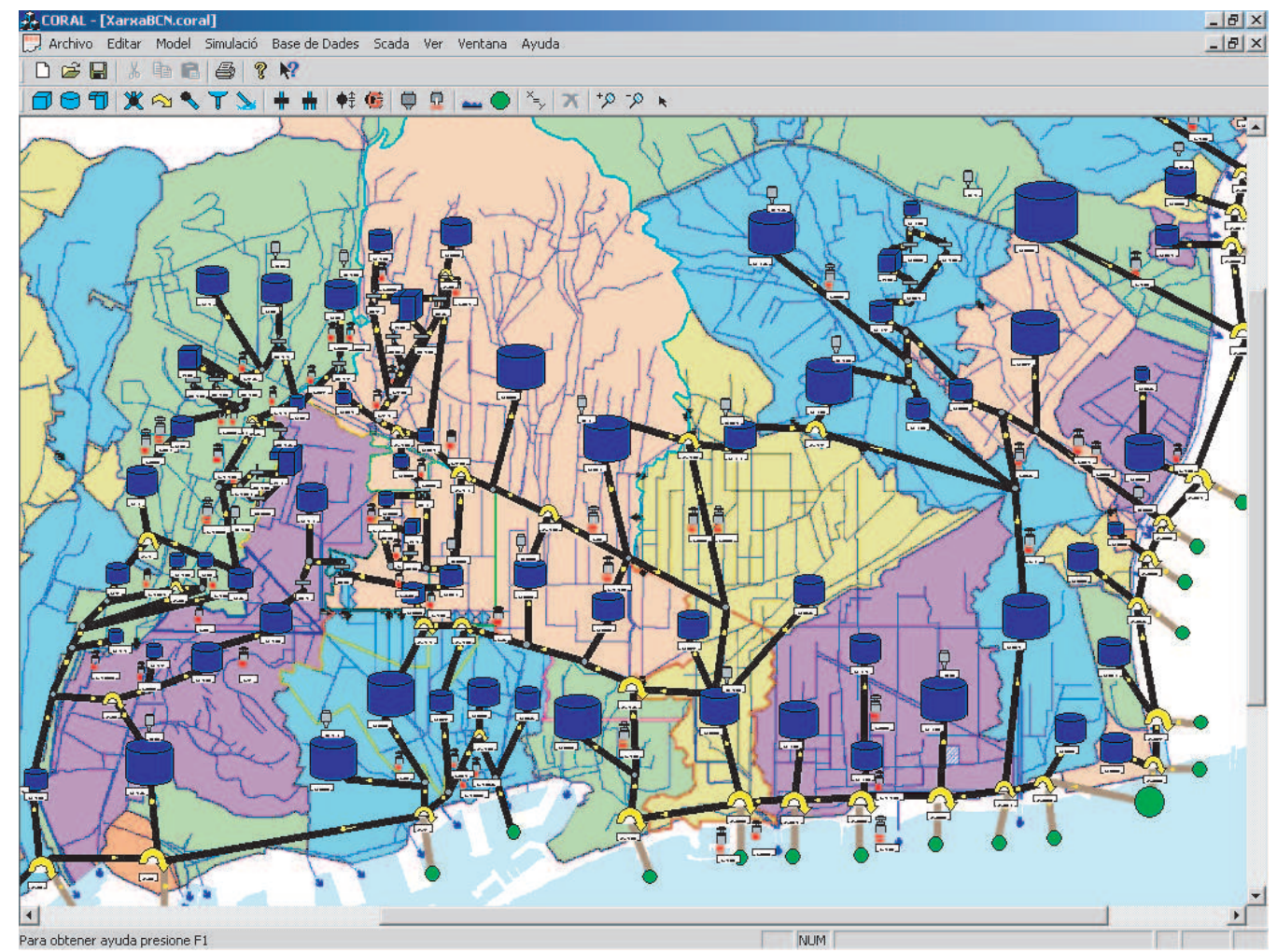

Fig. 13. CORAL interface corresponding to the model manager module than allows creating/updating the model of the sewer network in graphical way using the virtual modeling approach.

CORAL is a general-purpose decision support tool that allows the user to apply and implement in real-time predictive optimal control techniques in large-scale urban drainage/sewer systems [40], [18]. The model methodology used by this software tool is described in the modeling section of this article. CORAL has been jointly developed by CLABSA and UPC and has been already tested off-line in Escola Industrial and Riera Blanca test catchments of the Barcelona sewer network as described in [6] and [27]. It was also tested on the Murcia (Spain) network to study the feasibility and potential benefits of the construction of three detention tanks and the use of flow diversion gates. CORAL was developed jointly by the AGBAR Group and SAC (Advanced Control Systems Group) at UPC (Universitat Politècnica de Catalunya) and CSIC (Spanish National Research Council). Currently, CORAL is also in the process of becoming a commercial product Aqualogy AquaAmbiente S.A. 


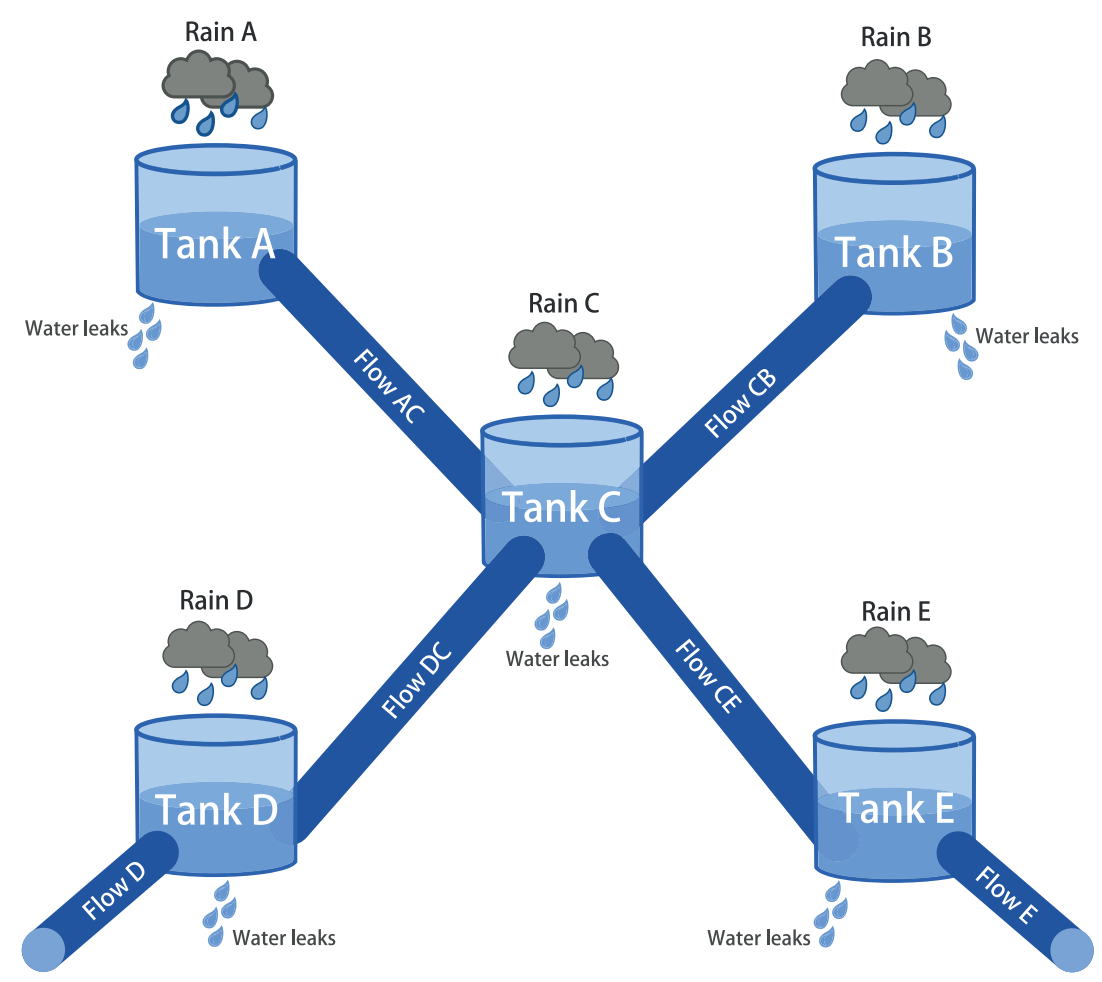

Fig. 14. Sewer network modeling by means of interconnected virtual tanks. Each tank represents a catchment in the sewer network.

At any given time, let the virtual tank be a storing element that represents the total volume of sewage inside the sewer mains associated with a determined sub-catchment of a given sewer network. The sewage volume is computed through the mass balance of the stored volume, the inflows and outflows related to the sewage mains and the equivalent inflow associated with the rain water [24], [25], [14]. 


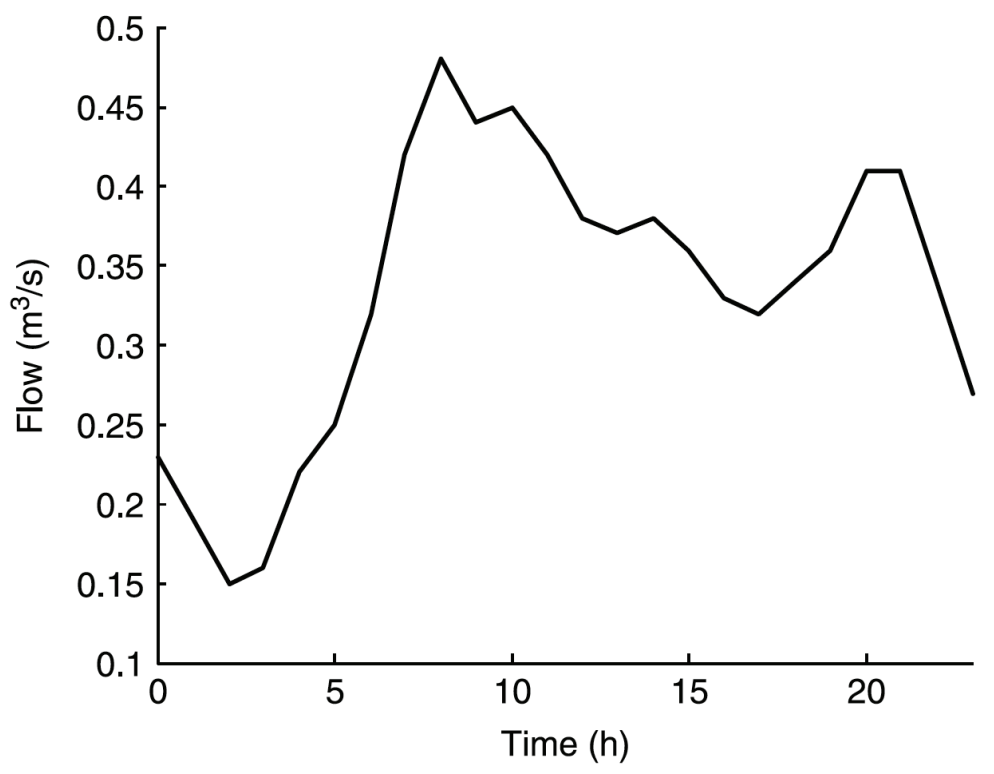

Fig. 15. Hourly pattern of a demand sector that repeats periodically every day.

\section{Sidebar S5: Water Demand Forecast}

Demand forecasting plays an important role in the efficient management of a DWN since allows to program the pumping arrangements over the next 24 hours taking advantage of the electricity tariff structure. A review of the scientific literature confirms that a considerable amount of effort has been expended on water-demand forecasting. In the case of operational control, the interest is restricted to short term time scale (hourly/daily) rather than annual/monthly which is used for longer-term waterresources planning. Most of the developed methodologies for hourly forecasts exploit the recurring patterns and periodicities that exist in water-demand data, at different levels of temporal aggregation. A detailed analysis of the observed hourly and daily water-demand time-series revealed the existence of patterns in which it is possible to identify seasonal and weekly periodicities in daily water demands as well as daily periodicities in hourly water demands. Figure 15 shows a demand profile corresponding to the 24-hour demand distribution in one demand sector. Similar demand patterns are used on all demand locations. From the literature analysis, the most used methods developed for short-term demand forecast relies in the combined used of time-series analysis and demand patterns [19], [47]. 


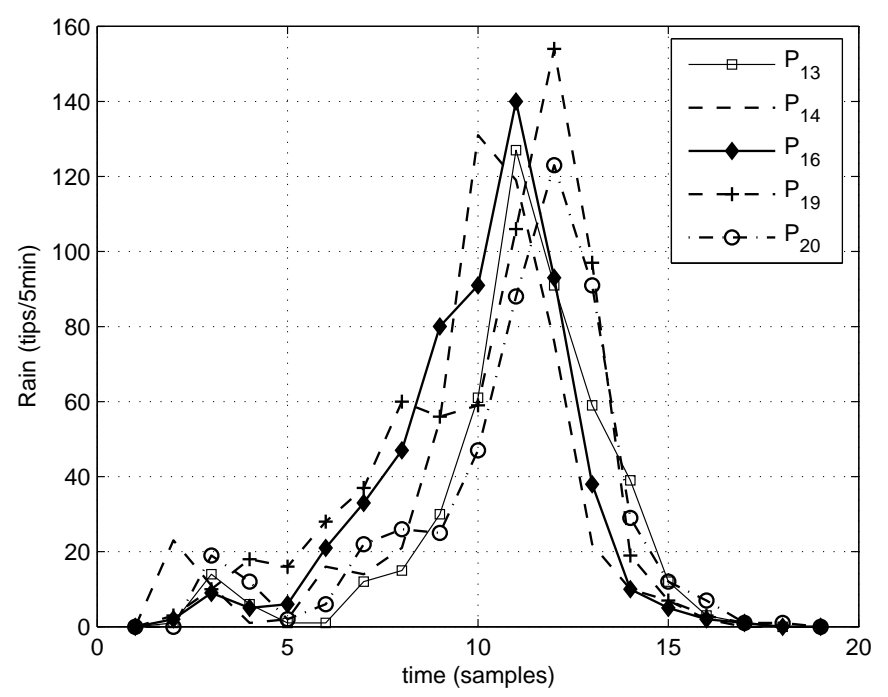

Fig. 16. Heavy rain scenario occurred at Barcelona on September 14, 1999. It can be seen that the big peak of rain in a very short time period.

\section{Sidebar S6: Rain InTEnsity Forecast}

Radar and rain gauges are the most common measurements for collecting rainfall data. Together with rainfall radar, rain gauges are widely used to estimate the areal and spatial distribution of rainfall. Unlike rainfall radar which can estimate rainfall at a high resolution over a large area, rain gauges can only measure rainfall directly at point locations (see Figure 16) to observe rainfall readings provided by the rain-gauges of the Barcelona sewer network during a real rain scenario. As a remote sensing observation, rainfall radar can allow the prediction of short-term forecasts based on the current weather situation, which can provide useful information on rainfall distribution. Rainfall occurrence in a particular area can be studied in order to provide the rainfall rate which can then be used in the future for predicting rainfall levels for similar weather situations. Although radar detection is affected by problems such as ground occlusion and altitude effects, it could be very useful and efficient in short-term forecasting which is also called nowcasting. Weather radars transmit a pulse of radio waves and detect any rainfall mass through detection of electromagnetic reflection. More precisely, a reflectivity-rainfall $(Z-R)$ relationship is built to produce reliable radar-based predictions of rainfall intensities applying radar reflectivity data. The rain intensity $R$ is related to the radar reflection $Z$ according to the power law. The rainfall amounts can be estimated involving the use of reflection by means of the $Z-R$ relation. In this way, the weather radars have the potential to estimate the rainfall. Recently, it has been proved that the prediction based on weather radar yielded a satisfactory result with a small average error rate and also proved to be accurate, even more accurate in totaling rainfall than rain gauge models in some cases.

\section{REFERENCES}

[1] J. B. Hewitson, A. Busuioc, A. Chen, X. Gao, I. Held, R. Jones, R. Kolli, W. T. Kwon, R. Laprise, V. M. Rueda, L. Mearns, C. Menéndez, J. Räisänen, A. Rinke, A. Sarr, and P. Whetton, "Regional climate projection," in Climate Change 2007: The Physical Science Basis. Contribution of Working Group I to the Fourth Assessment Report of the IntergovernmentalPanel on Climate Change (S. Solomon, D. Qin, M. Manning, Z. Chen, M. Marquis, K. Averyt, M. Tignor, and H. Miller, eds.), Cambridge, United Kingdom and New York, NY, USA.: Cambridge University Press, 2007.

[2] C. Ocampo-Martinez, A. Ingimundarson, V. Puig, and J. Quevedo, "Objective prioritization using lexicographic minimizers for MPC of sewer networks," IEEE Transactions on Control Systems Technology, vol. 16, no. 1, pp. 113-121, 2008.

[3] J. Rawlings and D. Mayne, Model Predictive Control: Theory and Design. Madison, WI (USA): Nob Hill Publishing, 2009.

[4] C. Ocampo-Martinez, D. Barcelli, V. Puig, and A. Bemporad, "Hierarchical and decentralised model predictive control of drinking water networks: Application to the Barcelona case study," IET Control Theory \& Applications, vol. 6, no. 1, pp. 62 - 71, 2012.

[5] G. Cembrano, G. Wells, J. Quevedo, R. Pérez, and R. Argelaguet, "Optimal control of a water distribution network in a supervisory control system," Control Engineering Practice, vol. 8, no. 10, pp. 1177-1188, 2000. 
[6] G. Cembrano, J. Quevedo, M. Salamero, V. Puig, J. Figueras, and J. Martí, "Optimal control of urban drainage systems: a case study," Control Engineering Practice, vol. 12, no. 1, pp. 1-9, 2004.

[7] M. Marinaki and M. Papageorgiou, Optimal Real-time Control of Sewer Networks. Secaucus, NJ (USA): Springer, 2005.

[8] P. V. Overloop, Model Predictive Control on Open Water Systems. Delft, The Netherlands: Delft University Press, 2006.

[9] M. Schütze, A. Campisanob, H. Colas, W.Schillingd, and P. Vanrolleghem, "Real time control of urban wastewater systems: Where do we stand today?," Journal of Hydrology, vol. 299, pp. 335-348, 2004.

[10] M. Blanke, M. Kinnaert, J. Lunze, and M. Staroswiecki, Diagnosis and Fault-Tolerant Control. Berlin, Heidelberg: Springer-Verlag, second ed., 2006.

[11] D. G. Jamieson, U. Shamir, F. Martinez, and M. Franchini, "Conceptual design of a generic, real-time, near-optimal control system for water-distribution networks," Journal of Hydroinformatics, vol. 9, no. 1, pp. 3-14, 2007.

[12] P. Skworcow, B. Ulanicki, H. AbdelMeguid, and D. Paluszczyszyn, "Model predictive control for energy and leakage management in water distribution systems," in Proceedings of the UKACC International Conference on Control, (Coventry, UK), 2010.

[13] S. Darsono, , and J. W. Labadie, "Neural-optimal control algorithm for real-time regulation of in-line storage in combined sewer systems.," Environmental Modelling and Software, vol. 22, no. 9, pp. 1349-1361, 2007.

[14] C. Ocampo-Martinez, Model Predictive Control of Wastewater Systems. Advances in Industrial Control, Springer Verlag, 1 ed., 2011. ISBN: 978-1-84996-352-7.

[15] L. Mays, Urban Stormwater Management Tools. USA: McGrawHill Professional Publishing, 2004.

[16] M. Brdys and B. Ulanicki, Operational Control of Water Systems: Structures, algorithms and applications. UK: Prentice Hall International, 1994.

[17] C. Ocampo-Martinez, V. Puig, G. Cembrano, R. Creus, and M. Minoves, "Improving water management efficiency by using optimizationbased control strategies: the Barcelona case study," Water Science \& Technology: Water supply, vol. 9, no. 5, pp. 565-575, 2009.

[18] G. Cembrano, J. Quevedo, V. Puig, R. Pérez, J. Figueras, J. M. Verdejo, I. Escaler, G. Ramón, G. Barnet, P. Rodríguez, and M. Casas, "Plio: A generic tool for real-time operational predictive optimal control of water networks," Water Science and Technology (to appear), 2011.

[19] J. Quevedo, V. Puig, G. Cembrano, and J. Blanch, "Validation and reconstruction of flow meter data in the Barcelona water distribution network," Control Engineering Practice, vol. 11, pp. 640-651, June 2010.

[20] J. Quevedo, G. Cembrano, A. Valls, and J. Serra, Computer applications in water supply, vol. I, ch. Time series modelling of water demand: A study on short-term and long-term predictions, pp. 268 - 288. Lechworth, England: Research Studies Press, 1988.

[21] M. Marinaki and M. Papageorgiou, "Nonlinear optimal flow control for sewer networks," in Proceedings of the American Control Conference, vol. 2, (Philadelphia, Pennsylvania, USA), pp. 1289-1293, 1998.

[22] Y. Ermolin, "Mathematical modelling for optimized control of Moscow's sewer network," Applied Mathematical Modelling, vol. 23, pp. 543-556, 1999.

[23] S. Duchesne, A. Mailhot, E. Dequidt, and J. Villeneuve, "Mathematical modeling of sewers under surcharge for real time control of combined sewer overflows," Urban Water, vol. 3, pp. 241-252, 2001.

[24] M. Gelormino and N. Ricker, "Model predictive control of a combined sewer system," International Journal of Control, vol. 59, pp. 793-816, 1994

[25] J. Ballester, J. Martí, and M. Salamero, "Control de compuertas de derivación en la red de alcantarillado de Barcelona," Ingeniería del Agua, vol. 5, no. 4, pp. 37-46, 1998.

[26] V. Singh, Hydrologic Systems. Volume I: Rainfall-Runoff Modeling. Englewood Cliffs, New Jersey: Prentice Hall, 1988.

[27] V. Puig, G. Cembrano, J. Romera, J. Quevedo, B. Aznar, G. Ramón, and J. Cabot, "Predictive optimal control of sewer networks using CORAL tool: Application to Riera Blanca catchment in Barcelona," Water Science \& Technology, vol. 60, no. 4, pp. 869-878, 2009.

[28] F. Previdi, M. Lovera, and S. Mambretti, "Identification of the rainfall-runoff relationship in urban drainage networks," Control Engineering Practice, vol. 7, pp. 1489-1504, 1999.

[29] C. Ocampo-Martinez, A. Bemporad, A. Ingimundarson, and V. Puig, Identification and Control: The Gap between Theory and Practice, ch. On Hybrid Model Predictive Control of Sewer Networks, pp. 87 - 114. Springer-Verlag, 2007.

[30] W. Heemels, B. De Schutter, and A. Bemporad, "Equivalence of hybrid dynamical systems," Automatica, vol. 37, no. 7, pp. 1085-1091, 2001.

[31] C. Ocampo-Martinez and V. Puig, "Piece-wise linear functions-based model predictive control of large-scale sewage systems," IET Control Theory \& Applications, vol. 4, no. 9, pp. 1581-1593, 2010.

[32] C. Ocampo-Martinez, V. Fambrini, D. Barcelli, and V. Puig, "Model predictive control of drinking water networks: A hierarchical and decentralized approach," in Proceedings of the American Control Conference, (Baltimore (USA)), pp. 3951 - 3956, 2010.

[33] A. Chen and X. Xu, "Goal programming approach to solving network design problem with multiple objectives and demand uncertainty," Expert Systems with Applications, vol. 39, no. 4, pp. 4160 - 4170, 2012.

[34] R. Toro, C. Ocampo-Martinez, F. Logist, J. V. Impe, and V. Puig, "Tuning of predictive controllers for drinking water networked systems," in Proceedings of the IFAC World Congress, (Milano (Italy)), 2011.

[35] J. Maciejowski, Predictive Control with Constraints. Great Britain: Prentice Hall, 2002.

[36] E. Camacho and C. Bordons, Model Predictive Control. Springer-Verlag, London, second ed., 2004.

[37] G. Calafiore and F. Dabbene, Probabilistic And Randomized Methods for Design Under Uncertainty. Springer, 2006.

[38] A. Shapiro, D. Dentcheva, and A. Ruszczynski, Lectures on stochastic programming: modeling and theory. Society for Industrial and Applied Mathematics and Mathematical Programming Society, 2009.

[39] J. M. Grosso, "A robust adaptive Model Predictive Control to enhance the management of drinkingwater networks subject to demand uncertainty and actuators degradation," Master's thesis, Technical University of Catalonia (UPC), Barcelona, 2012.

[40] J. Figueras, G. Cembrano, V. Puig, J. Quevedo, M. Salamero, and J. Martí, "Coral off-line: an object-oriented tool for optimal control of sewer networks," in Proceedings on IEEE International Symposium on computer-aided control system design, vol. 1, (Glasgow, Scotland (UK)), pp. 224-229, 2002. 
[41] J. Abadie and J. Carpentier, Optimization, ch. Generalization of the Wolfe reduced gradient method to the case of nonlinear constraints, pp. 37 - 47. New York: Academic Press, 1969.

[42] A. Drud, "CONOPT -a large-scale GRG code," Journal on Computing, vol. 6, pp. 207 - 216, 1992.

[43] C. Ocampo-Martinez, S. Bovo, and V. Puig, "Partitioning approach oriented to the decentralised predictive control of large-scale systems," Journal of Process Control, vol. 21, no. 5, pp. 775 - 786, 2011.

[44] C. Ocampo-Martinez, V. Puig, J. Grosso, and S. M. de Oca, DMPC made easy, ch. Multi-layer Decentralized Model Predictive Control of Large-Scale Networked Systems. Springer, 2013. To appear.

[45] G. Cembrano, J. Figueras, J. Quevedo, V. Puig, M. Salamero, and J. Marti, "Global control of barcelona sewerage system for environment protection," in Proceedings of IFAC World Congress, (Barcelona (Spain)), pp. 1-6, 2002.

[46] R. K. Price, "Hydroinformatics and urban drainage: An agenda for the 21st century," Journal of Hydroinformatics, vol. 2, no. 2, pp. 133-147, 2000.

[47] S. Alvisi, M. Franchini, and A. Marinelli, "A short-term, pattern-based model for water-demand forecasting," Journal of Hydroinformatics, vol. 9, no. 1, pp. 39-50, 2007. 


\section{AUTHORS' INFORMATION}

Carlos Ocampo-Martinez received his Electronic Engineering degree and his MSc degree in Industrial Automation from the National University of Colombia, Campus Manizales, in 2001 and 2003, respectively. In 2007, he received his PhD Degree in Control Engineering from the Technical University of Catalonia (Barcelona, Spain). After a year as postdoctoral fellow of the ARC Centre of Complex Dynamic Systems and Control (University of Newcastle, Australia), he was with the Spanish National Research Council (CSIC) at the Institut de Robòtica i Informàtica Industrial (IRI) in Barcelona as a Juan de la Cierva research fellow. Since 2011, he is Assistant Professor at the Technical University of Catalunya, Automatic Control Department (ESAII). His main research interests are in the areas of constrained model predictive control, large-scale systems management, nonlinear dynamics and industrial applications.

Vicenç Puig received the Telecommunications Engineering Degree in 1993 and the PhD Degree in Control Engineering in 1999, both from the Universitat Politècnica de Catalunya (UPC), Barcelona, Spain. He is currently Professor of Automatic Control and leader of the Advanced Control Systems (SAC) research group at the Universitat Politècnica de Catalunya. His main research interests are fault detection and isolation (FDI) of fault-tolerant control (FTC) of dynamic systems as well as model predictive control of large-scale systems with special emphasis on water systems. He has been involved in several European projects and networks and has published about 200 papers in international conference proceedings and about 45 in scientific journals.

Gabriela Cembrano received her MSc and $\mathrm{PhD}$ degrees in Industrial Engineering from the Universitat Politècnica de Catalunya (UPC) in 1984 and 1988, respectively. Since 1989, she is a tenured researcher of the Spanish National Research Council (CSIC) at the Insitut de Robòtica i Informàtica Industrial. Her main research area is Control Engineering and she has been involved in industrial projects on Modelling and Optimal Control of water supply, distribution and urban drainage systems since 1985. She is also a member of CETaqua - Water Technology Center - funded by the water company AGBAR, UPC and CSIC, as head of one of six main research lines of the center. She has taken part in several Spanish and European research projects in the field of Advanced Control and especially its application in water systems. She is now the main researcher of the project WATMAN (Analysis and Design of distributed optimal control strategies applied to large-scale Water systems Management) funded by the Spanish Ministry of Science and Innovation, and Scientific Director of EC project EFFINET Integrated Real-time Monitoring and Control of Drinking Water Networks, reference FP7 ICT-318556 (2012-14).

Joseba Quevedo received the master degree in Electrical, Electronic and Control Engineering in 1973 and the PhD in Control Engineering by the University Paul Sabatier of Toulouse (France) in 1976 and the $\mathrm{PhD}$ in Computer Engineering by the Technical University of Catalonia in 1982. Since 1979 he is with the Technical University of Catalonia, where he is full professor since 1990. Joseba Quevedo has published more than 150 journal and conference articles in the areas of advanced control, identification and parameter estimation, fault detection, diagnosis and fault tolerant control and their applications to largescale systems (water distribution systems and sewer networks) and to industrial processes. He has taken part in several Spanish and European research projects in the field of advanced control and supervision and its application to complex systems as well as coordinated projects with national and international companies in the water and energy domains related to the improvement of optimal control of drinking water and sewer networks. He was the conference chairman of the XV IFAC World Congress in Barcelona (2002), the National Organizing Committee Chairman of the SAFEPROCESS in Barcelona (2009), andthe General Chairman of the Mediterranean Control and Automation Symposium (MED 2012) in Barcelona. 